\title{
A Numerical Study of Cirrus Clouds. Part II: Effects of Ambient Temperature, Stability, Radiation, Ice Microphysics, and Microdynamics on Cirrus Evolution
}

\author{
Hui-Chun Liu, Pao K. Wang, And Robert E. Schlesinger \\ Department of Atmospheric and Oceanic Sciences, University of Wisconsin-Madison, Madison, Wisconsin
}

(Manuscript received 2 November 2000, in final form 5 December 2002)

\begin{abstract}
Using the numerical cirrus cloud model developed in Part I of this study, the development of cirrus is examined for four different environmental regimes: warm unstable, cold unstable, warm stable, and cold stable. Despite similar initial saturation conditions, the clouds in the warm and cold cases develop very differently. As summarized below, these four simulations suggest that homogeneous freezing of haze particles and cold temperatures are two major reasons for persistent cirrus clouds. The numerical model is also used here to investigate the roles of several other physical factors in cirrus evolution for a selected environmental regime. These additional factors are radiation, ice crystal habit, latent heat, and ice crystal aggregation.

In the warm unstable case, ice particles quickly grow large enough to fall out of the initially supersaturated cloud generation region into the subsaturated lower region. But in the cold unstable case, due to slow growth of cold temperatures, sedimentation is greatly postponed. Thus the cold cirrus tends to persist longer than the warm cirrus.

In the unstable cases, diabatic heating tends to slightly destabilize the upper part of the cloud, whose circulation thus is most persistent near the cloud top. The circulation transports water vapor upward to enable long-lasting new ice particle generation.

The solar heating tends to be concentrated near the cloud top in both unstable cases, but with quite different IR heating profiles. The IR heating warms the warm cloud near the base and cools it near the top, whereas the cold cloud is radiatively warmed throughout, mostly because it is optically thinner than the warm cloud.

In the stable cases, homogeneous nucleation (the homogeneous freezing of haze solution droplets, as parameterized in Part I of this paper) does not occur for the parameterization of heterogeneous nucleation used, leaving the number concentration of ice much smaller than in the unstable cases. However, the individual crystals can grow larger, due to less competition for water vapor, so that they fall out of the initial saturated layer faster than in the unstable cases. The sedimentation rate is slower in the cold stable case than in the warm stable one, again due to slower growth rates at cold temperatures. In neither stable case does the induced diabatic heating destabilize the cloud layer.

In this numerical study, it is found that cirrus cloud becomes much less persistent in the simulation without any radiative processes. For warm cirrus, the growth is slightly more vigorous in the daytime than at night, while the opposite is true for cold cirrus. It is found that latent heating plays two opposite roles in the evolution of cirrus. First, it augments the initial perturbation in the growing stage of the cloud, but then tends to stabilize the cloud layer, limiting the development of cirrus at later stages of the cloud evolution. Ice crystal habit has great impact on the evolution of cirrus, especially in an unstable atmosphere. The radiative heating rates are also found to be very sensitive to the type of ice crystal in the cloud. Finally, the role of ice aggregates in the evolution of cirrus is also explored. It is found that the aggregates reduce the volume absorption coefficient, thus decreasing the optical depth and tending to reduce the radiative destabilization.
\end{abstract}

\section{Introduction}

There have been several attempts to develop numerical models to investigate the role of various physical processes in the life cycle of cirrus clouds. Jensen et al. (1994a,b) developed a one-dimensional cirrus cloud formation model that includes explicit simulation of the size distribution of ice crystals involving a number of

Corresponding author address: Dr. Pao K. Wang, Department of Atmospheric and Oceanic Sciences, University of Wisconsin-Madison, 1225 W. Dayton Street, Madison, WI 53706-1695. E-mail: pao@windy.meteor.wisc.edu microphysical processes. Their model produces reasonable ice water content (IWC) but low ice crystal number densities, possibly because of its one-dimensional nature. As pointed by Gultepe and Starr (1995), cirrus clouds are a dynamic and thermodynamic system that involves the intricate coupling of microphysics, radiation, and dynamic processes, and hence requires multidimensional settings to account for interaction and feedback studies. In their pioneering work, Starr and Cox (1985a,b) developed a two-dimensional model and showed that the effects of radiative processes and vertical transports are both significant in cirrus cloud formation and maintenance. Gu and Liou (1997a,b) con- 
TABLE 1. Important environmental and microphysical factors for cirrus clouds.

\begin{tabular}{|c|c|}
\hline Parameters & Combinations \\
\hline Cloud height (temperature) & Warm vs cold cirrus \\
\hline Large-scale forcing & $\begin{array}{l}\text { Weak vs strong vertical uplifting } \\
\text { - Cirrus uncinus: } 100-150 \mathrm{~cm} \mathrm{~s}^{-1} \\
\text { - Warm front overrunning: } 2-10 \mathrm{~cm} \mathrm{~s}^{-1} \text {. } \\
\text { - Warm front occlusion: } 20 \mathrm{~cm} \mathrm{~s}^{-1} \\
\text { - Closed low aloft: } 25-50 \mathrm{~cm} \mathrm{~s}^{-1}\end{array}$ \\
\hline Horizontal wind shear & $\begin{array}{l}\text { No shear vs weak to strong shear (usually positive), ranging } \\
\text { from about } 4 \mathrm{~m} \mathrm{~s}^{-1} \mathrm{~km}^{-1} \text { in summer to } 6.5 \mathrm{~m} \mathrm{~s}^{-1} \mathrm{~km}^{-1} \text { in } \\
\text { winter }\end{array}$ \\
\hline Time of day & $\begin{array}{l}\text { Nighttime vs daytime (thermal infrared only vs solar and ther- } \\
\text { mal infrared radiation) }\end{array}$ \\
\hline Stability (thermal stratification) & $\begin{array}{l}\text { Stable conditions vs conditionally unstable condition; quite var- } \\
\text { iable. }\end{array}$ \\
\hline \multirow[t]{4}{*}{ Ice crystal habit } & Hexagonal columns \\
\hline & Bullet rossettes \\
\hline & Hexagonal plates \\
\hline & Spheres (assumed by most models) \\
\hline Cloud condensation nuclei composition and concentration & $\left(\mathrm{NH}_{4}\right)_{2} \mathrm{SO}_{4}$ vs $\mathrm{H}_{2} \mathrm{SO}_{4}$ \\
\hline
\end{tabular}

structed a 2D cirrus model that includes a second-order turbulence closure and found that turbulence can significantly modulate the supersaturation condition and hence affect the rate at which water vapor is converted to ice. Their ice microphysical processes are parameterized in terms of IWC in these models in which the excess moisture is entirely converted to IWC in just one time step. Later, Lin (1997) has incorporated explicit microphysics schemes in 2D models for the simulation of ice crystal size distributions. More recently, Gu and Liou (2000) conducted further studies on the interactions of radiation, microphysics, and turbulence in the evolution of cirrus clouds based on an improved version of their earlier model.

A wide range of possible environmental and microphysical factors may significantly influence the development of cirrus clouds. Table 1 lists several parameters and combinations that are important for cirrus clouds. Among these factors are environmental forcing parameters such as large-scale lifting and static stability, some measure of the altitude of the cirrus layer (layer-mean height, temperature or pressure), the in-cloud ice crystal habit, and the time of day. Cirrus cloud layers are, in general, statically stable in an absolute sense, with lapse rate less than moist adiabatic with respect to either liquid water or ice. Some cirrus clouds overlie stable layers, indicating that they are associated with upper-level fronts. Others underlie stable layers, indicating that they are located just below the tropopause. The First International Satellite Cloud Climatology Project (ISCCP) Regional Experiment (FIRE) observation revealed that cirrus could also be found in a conditionally unstable environment with a lapse rate slightly greater than moist adiabatic but considerably less than dry adiabatic.

As has been pointed out by Ackerman et al. (1988), the in-cloud heating rates and cloud-base warming due to thermal infrared heating in cirrus are very sensitive functions of cloud altitude and thickness. In addition, the altitude of high cirrus clouds makes the task of measuring their microphysical properties by in situ aircraft a difficult challenge. In view of this logistical obstacle, a suitably designed numerical model of such clouds may serve a useful source of information about them with regard to these otherwise difficult-to-obtain parameters.

Accordingly, this paper addresses the above challenge by applying a two-dimensional quasi-compressible numerical cirrus cloud model, whose structure has been described in detail by Liu et al. (2003, hereafter Part I), to investigate the comparative evolution of cirrus for different combinations of ambient temperature and stability. In addition, the effects of radiation, ice microphysics, and microdynamics on the evolution of cirrus are also investigated. Yet another important factor, vertical wind shear, is not considered here but is left for future studies.

Four simulation sets are designed for the numerical investigations. Their setup is described below and summarized in Table 2.

- The first set considers two types of atmospheric stratification, one statically stable and the other featuring a conditionally stable layer overlying a stable one. This simulation set combines the environmental temperature and static stability parameters to form four kinds of atmospheric background profiles: cold stable, cold unstable, warm stable, and warm unstable, meant to schematize typical environments for cirrus. Atmospheric profiles representing these four cases were made available by a cirrus observation group at the National Aeronaotics and Space Administration (NASA) Global Energy and Water Cycle Experiment (GEWEX) Cloud System Study (GCSS) Working Group 2 (WG2) and are considered to be representative for specific seasons and locations. Four simulation cases are designed by using these four profiles as background. Ice crystals are assumed to be columns 
TABLE 2. Summary of simulation sets I-IV.

\begin{tabular}{|c|c|c|c|c|c|}
\hline \multicolumn{6}{|c|}{ Simulation set I } \\
\hline & Habit & Temperature zone & Static stability & Aggregation process & Radiative process \\
\hline 1 & Columns & Warm & Unstable & Yes & Daytime \\
\hline 2 & Columns & Warm & Stable & Yes & Daytime \\
\hline 3 & Columns & Cold & Unstable & Yes & Daytime \\
\hline 4 & Columns & Cold & Stable & Yes & Daytime \\
\hline \multicolumn{6}{|c|}{ Simulation set II } \\
\hline & Habit & Temperature zone & Static stability & Aggregation process & Radiative process \\
\hline 1 & Columns & Warm & Unstable & Yes & Daytime \\
\hline 2 & Columns & Warm & Unstable & Yes & Nighttime \\
\hline 3 & Columns & Warm & Unstable & Yes & No \\
\hline 4 & Columns & Cold & Unstable & Yes & Daytime \\
\hline 5 & Columns & Cold & Unstable & Yes & Nighttime \\
\hline 6 & Columns & Cold & Unstable & Yes & No \\
\hline \multicolumn{6}{|c|}{ Simulation set III } \\
\hline & Habit & Temperature zone & Static stability & Aggregation process & Diabatic process \\
\hline 1 & Columns & Warm & Unstable & Yes & Daytime \\
\hline 2 & Columns & Warm & Unstable & Yes & Daytime, No Qc \\
\hline 3 & Columns & Warm & Unstable & Yes & No \\
\hline \multicolumn{6}{|c|}{ Simulation set IV } \\
\hline & Habit & Temperature zone & Static stability & Aggregation process & Radiative process \\
\hline 1 & Columns & Warm & Stable & No & Daytime \\
\hline 2 & Plate & Warm & Stable & No & Daytime \\
\hline 3 & Rosettes & Warm & Stable & No & Daytime \\
\hline 4 & Spheres & Warm & Stable & No & Daytime \\
\hline 5 & Columns & Cold & Stable & No & Daytime \\
\hline 6 & Plate & Cold & Stable & No & Daytime \\
\hline 7 & Rosettes & Cold & Stable & No & Daytime \\
\hline 8 & Sphere & Cold & Stable & No & Daytime \\
\hline 9 & Columns & Warm & Unstable & Yes & Daytime \\
\hline 10 & Rosettes & Warm & Unstable & Yes & Daytime \\
\hline 11 & Columns & Cold & Unstable & Yes & Daytime \\
\hline 12 & Rosettes & Cold & Unstable & Yes & Daytime \\
\hline 13 & Columns & Warm & Stable & Yes & Daytime \\
\hline 14 & Columns & Cold & Stable & Yes & Daytime \\
\hline
\end{tabular}

and ice aggregation is included in all cases in this simulation set. Simulation time is daytime, so that both solar and terrestrial radiation processes are included.

- The second set is designed to examine the effect of radiation on cirrus development. These experiments simulate daytime (solar and terrestrial radiation), nighttime (terrestrial radiation only), and a hypothetical situation in which we turn off both solar and terrestrial radiation, and the results of all these cases are then compared. The warm unstable and cold unstable background profiles are used in the set. Columnar crystals are assumed, and ice aggregation is also included in all cases in this set.

- The third simulation set is intended to examine the effect of latent heating, as it may play a role in changing the vertical temperature profile in the cirrus cloud and thus affect cloud development. Three cases are designed to determine the role of latent heating in cirrus development. One case retains full diabatic processes, the second turns off latent heating, and the third turns off all diabatic heating. The warm unstable profile is considered in all three cases. Columnar ice is assumed, and aggregation is included.

- The fourth set of experiments is motivated by the fact that three types of ice crystals are commonly observed in cirrus: columns, plates, and bullet rosettes. Each crystal type has a different capacitance and ventilation coefficient, as discussed in Part I. The ice crystal growth rate is a very sensitive function of crystal habit, since it depends largely on the capacitance and ventilation coefficient. Thus, the evolution of cirrus may be strongly influenced by the type of ice crystal in the cloud. Accordingly, we also consider the effect of ice crystal habit on the development of cirrus by varying the habit. In addition to the aforementioned crystal types, ice spheres are also considered. This is done because spherical shapes are widely used for the sake of simplicity, so it is of interest to test the validity of this assumption. Moreover, the influence of ice aggregation on the development of cirrus is also investigated. The process is not well understood, especially for cold clouds, and the present study seeks to shed some light by simulating cases with and without ag- 


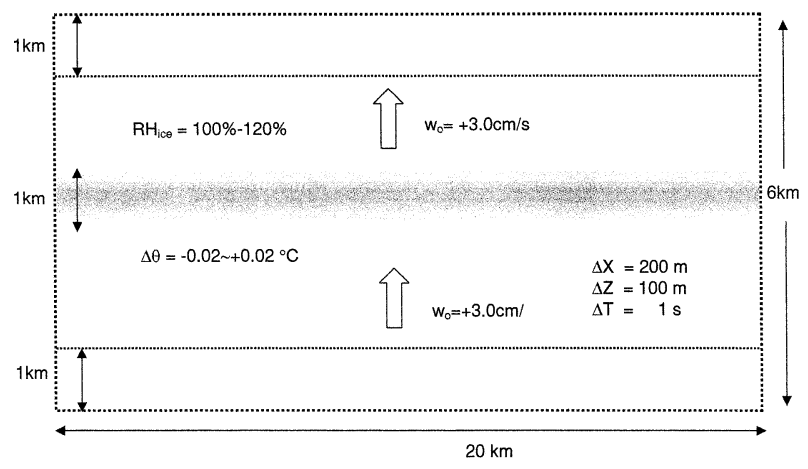

FIG. 1. Schematic of the model domain.

gregation and comparing their results. Thus, this simulation set is designed to investigate the influence of ice crystal habit including aggregation. Cold and warm stable profiles are used in this set.

Weak large-scale ascent, uniformly set to $3 \mathrm{~cm} \mathrm{~s}^{-1}$, is used for all four simulation sets in this paper. This small value is chosen because the temperature change resulting from adiabatic expansion in this ascent is weak enough so that the temperature changes from radiative effects become dominant, facilitating our examination of radiative effects on the development of cirrus. Moreover, background vertical motions of $2-3 \mathrm{~cm} \mathrm{~s}^{-1}$, deduced from synoptic-scale rawinsonde networks, are very typical for observed fair-weather cirriform clouds.

Further details concerning the layout of our cirrus simulations are presented in section 2 , followed by a comprehensive description of the results in section 3 , and a concluding summary in section 4 .

\section{Model setup and initializations}

The model domain illustrated in Fig. 1 represents a cross section of cirrus advected by a nonsheared mean wind. The initial supersaturated layer is about $1 \mathrm{~km}$ thick. Temperature in the supersaturated layer is randomly perturbed between $-0.02^{\circ}$ and $0.02^{\circ} \mathrm{C}$ to initialize the convective disturbance. The background temperature and moisture (and associated static stability) profiles will be presented in the next section. The background vertical motion is set to $3 \mathrm{~cm} \mathrm{~s}^{-1}$, a typical value for large-scale lifting, which is uniformly imposed throughout the model domain at all times.

The model domain is $20 \mathrm{~km}$ wide, and $6 \mathrm{~km}$ deep, with respective spatial resolutions of 200 and $100 \mathrm{~m}$. When a test was conducted with the grid mesh reduced to $100 \mathrm{~m}$ in the horizontal and $50 \mathrm{~m}$ in the vertical, the results did not show any obvious differences from those obtained using the $200 \mathrm{~m} \times 100 \mathrm{~m}$ grid cell configuration. There are four different time steps used in this model. In the dynamic module, a time step of $1.0 \mathrm{~s}$ is imposed for the large time step, while $0.1 \mathrm{~s}$ is used for the small time step. In order to reduce the computational time spent on radiative transfer, the radiation time step is usually set larger than the dynamic time step (Lin 1997). So, the radiative transfer module is evaluated at $30 \mathrm{~s}$. This indicates that the radiative heating rates remain constant during this $30 \mathrm{~s}$. The cloud microphysics module is evaluated every $0.5 \mathrm{~s}$.

The simulations performed are summarized in Table 2. As previously noted, four kinds of atmospheric background profiles are considered in this study: warm unstable, warm stable, cold unstable, and cold stable. The warm cirrus profiles are based on the U.S. Standard Spring Atmosphere at $45^{\circ} \mathrm{N}$. The cold cirrus profiles are based on the U.S. Standard Summer Atmosphere at $30^{\circ} \mathrm{N}$. Surface temperature is $15^{\circ} \mathrm{C}$ for warm cirrus, and $31.4^{\circ} \mathrm{C}$ for cold cirrus. The background tropospheric temperature lapse rate is $6.5^{\circ} \mathrm{C} \mathrm{km}^{-1}$ in the former standard profile, while there is more structure in the latter. The tropopause occurs at $10.5 \mathrm{~km}\left(-56.5^{\circ} \mathrm{C}\right)$ and 15.5 $\mathrm{km}\left(-76^{\circ} \mathrm{C}\right)$, respectively. The background tropospheric relative humidity is set to $40 \%$ with respect to a plane water surface. Background profiles shown in Fig. 2 include height, pressure, temperature, temperature lapse rate, and relative humidity with respect to plane ice surfaces are included. Temperature lapse rates for the warm unstable case are ice pseudoadiabatic from 8.0 to $8.5 \mathrm{~km}$, and $1^{\circ} \mathrm{C} \mathrm{km}^{-1}$ greater than ice pseudoadiabatic from 8.5 to $9.0 \mathrm{~km}$. Similarly, temperature lapse rates for the cold unstable case are ice pseudoadiabatic from 13 to $13.5 \mathrm{~km}$, and $1^{\circ} \mathrm{C} \mathrm{km}{ }^{-1}$ greater than ice pseudoadiabatic from 13.5 to $14 \mathrm{~km}$. For both statically stable cases, the lapse rates in these layers are set to $8^{\circ} \mathrm{C}$ $\mathrm{km}^{-1}$. Relative humidity with respect to ice is $100 \%$ at the base of the ice neutral layer and increases linearly with height to $120 \%$ at the base of the conditionally unstable layer, above which it is constant.

Some care must be taken regarding solar geometry, which is defined via a specification of latitude, date, and initial local solar time (LST). We choose 21 March (vernal equinox) for the warm cirrus case, and 21 June (summer solstice) for the cold cirrus case, running the simulations from 1300 to 1600 LST. Since the simulations are run for $3 \mathrm{~h}$, the corresponding solar zenith angle varies from $47.8^{\circ}$ to $69.9^{\circ}$ for the warm cirrus cases at $45^{\circ} \mathrm{N}$, and from $14.9^{\circ}$ to $53.4^{\circ}$ for the cold cirrus cases at $30^{\circ} \mathrm{N}$. In addition, we assume that the surface albedo is 0.2 , approximating a climatological average. The input parameters for the simulation sets are summarized in Table 3.

\section{Results and discussion}

The results from all the simulation sets performed are discussed in this section. Figure 3 shows the results of two ice water content contour plots from simulation set I. Figure $3 \mathrm{a}$ is for the warm unstable case, showing the ice water content at $60 \mathrm{~min}$, and Fig. $3 \mathrm{~b}$ is for the cold unstable case picturing the ice water content at $90 \mathrm{~min}$. Both plots reveal very typical cellular structure and ice crystal fallout streaks that are commonly observed in 

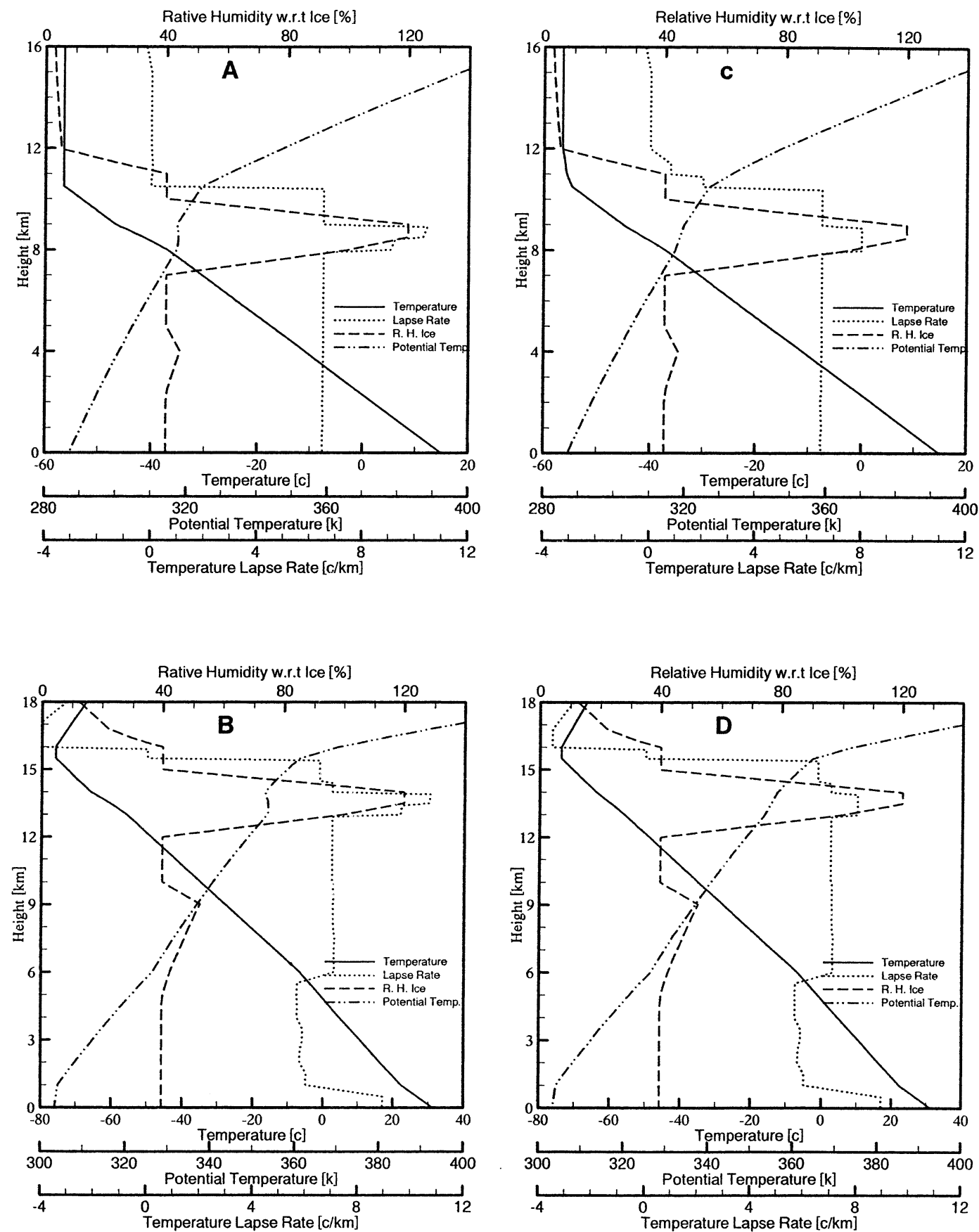

FIG. 2. Profiles of background atmospheric conditions. (a)-(d) Profiles for warm unstable, cold unstable, warm stable, and cold stable cases, respectively. Profiles include temperature, potential temperature, temperature lapse rate, and relative humidity with respect to ice.

cirrus clouds. The contour plots shown here are for demonstration purposes. In this paper, model variables such as ice water content, number concentration of ice, ice crystal size, relative humidity with respect to ice, water vapor flux, equivalent potential temperature, radiative heating rates, latent heating rate, vertical velocity, etc., are presented as horizontally averaged values and, in some cases, domain-averaged values. a. Simulation set I: Effect of ambient temperature and stability on cirrus evolution

\section{1) WARM unstable CASE}

The profiles of number concentration and water content for total ice, pristine ice, and ice aggregates in the warm unstable case are shown in Fig. 4. Different nucleation contributions to new ice formation were tracked 
TABLE 3. Definition of initial profiles.

\begin{tabular}{|c|c|}
\hline Definitions & \\
\hline Warm & $\begin{array}{l}\text { - U.S spring/fall atmosphere } \\
\text { - } 21 \text { Mar (Julian day } 80) \\
\text { - Location: } 45^{\circ} \mathrm{N} \\
\text { - Initial supersaturated layer: } \\
\text { Height: } 8-9 \mathrm{~km} \\
\text { Temperature: }-37^{\circ} \sim-48^{\circ} \mathrm{C} \\
\text { - Surface temperature: } 15^{\circ} \mathrm{C} \\
\text { - Surface Albedo: } 0.2 \\
\text { - Tropopause at } 10.5 \mathrm{~km}\left(-56.6^{\circ} \mathrm{C}\right) \\
\text { - Simulation time: } 1300-1600 \mathrm{LST} \\
\text { - Solar zenith angle: } 47.8^{\circ}-69.9^{\circ}\end{array}$ \\
\hline Cold & $\begin{array}{l}\text { - U.S. summer } \\
\text { - } 1 \text { Jun (Julian day 172) } \\
\text { - Location: } 30^{\circ} \mathrm{N} \\
\text { - Initial supersaturated layer: } \\
\text { Height: } 13-14 \mathrm{~km} \\
\text { Temperature: }-56^{\circ} \sim-68^{\circ} \mathrm{C} \\
\text { - Surface temperature: } 31.4^{\circ} \mathrm{C} \\
\text { - Surface albedo: } 0.2 \\
\text { - Tropopause at } 15.5 \mathrm{~km}\left(-76^{\circ} \mathrm{C}\right) \\
\text { - Simulation time: } 1300-1600 \mathrm{LST} \\
\text { - Solar zenith angle: } 14.9^{\circ}-53.4^{\circ}\end{array}$ \\
\hline Stable & $\begin{array}{l}\text { - Temperature lapse rate is } 8^{\circ} \mathrm{C} \mathrm{km}^{-1} \text { in the initial su- } \\
\text { persaturated layer }\end{array}$ \\
\hline Unstable & $\begin{array}{l}\text { - Temperature lapse rate is ice pseudoadiabatic lapse } \\
\text { rate for the lower } 0.5-\mathrm{km} \text { supersaturated layer } \\
\text { - Temperature lapse rate is } 1^{\circ} \mathrm{C} \mathrm{km} \mathrm{km}^{-1} \text { greater than the } \\
\text { ice pseudoadiabatic lapse rate for the upper } 0.5 \mathrm{~km}\end{array}$ \\
\hline
\end{tabular}

at every grid point and every time step. Many ice crystals are produced high in the cloud layer in the first 40 min of the simulation due to homogeneous nucleation, which begins at $14.4 \mathrm{~min}$ and ends around $37 \mathrm{~min}$. The ice number concentration in general increases from cloud base to the upper cloud layer, and then decreases sharply toward the cloud top. The peak number concentration starts to decay at about $40 \mathrm{~min}$, almost as soon as homogeneous nucleation ceases. This decay is apparently due to two reasons: 1) the fallout of ice crystals and 2) termination of homogeneous nucleation. The significant amount of ice crystals nucleated early in the simulation consumes relatively large amounts of water vapor, so that the nucleation process stops within a short time. Ice crystals grow very quickly during the first 40 min in the initial supersaturated layer, thus becoming heavy enough to fall out of the original supersaturated layer into the drier lower layer. By the end of the simulation, the ice number concentration becomes relatively uniform throughout the whole vertical layer. The total ice water content also peaks at about $40 \mathrm{~min}$ and then decays, generally assuming its largest values higher up in the cloud layer during the simulation. It can be seen that the cloud depth increases from $1 \mathrm{~km}$ in the initial supersaturated layer to $\sim 4 \mathrm{~km}$ by the end of the simulation, then extending approximately $2 \mathrm{~km}$ downward from the original supersaturated layer.

The number concentration and water content of ice aggregates are also shown in Fig. 4. Both at any given location are much smaller than for pristine ice during
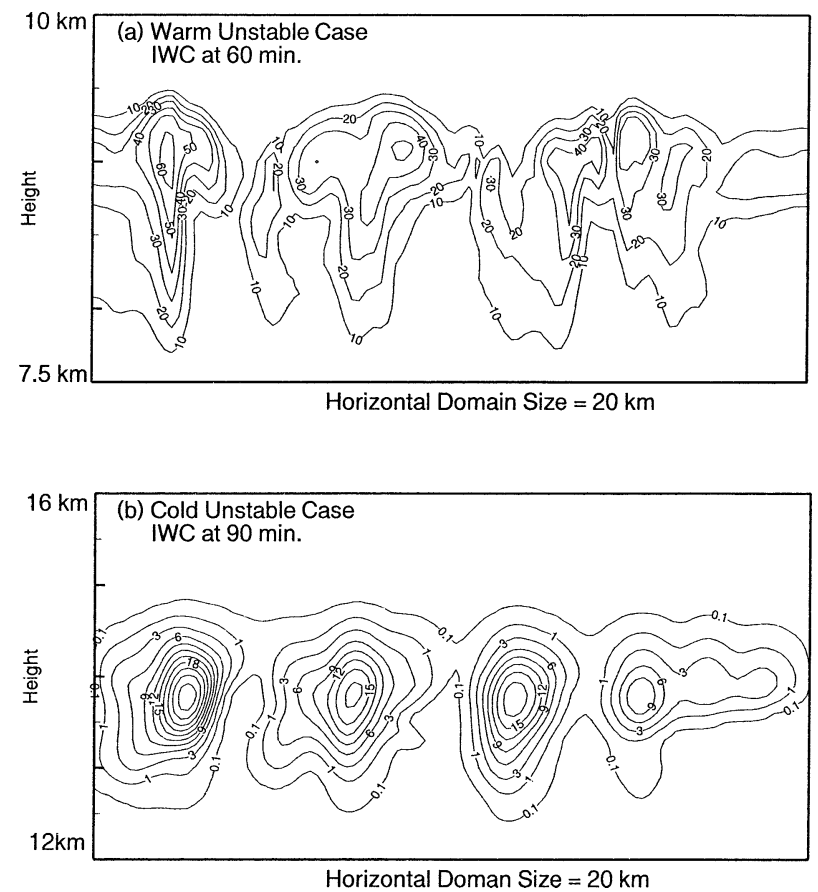

FIG. 3. (a) Contour plot of ice water content for warm unstable case at $30 \mathrm{~min}$. (b) Contour plot of ice water content for cold unstable case at $90 \mathrm{~min}$.

the simulation. As mentioned previously, the water content and number concentration of pristine ice both start to decay by $40 \mathrm{~min}$, but those of ice aggregates do not decay until $90 \mathrm{~min}$. The terminal velocities of ice crystals are, in general, small, and the differences among these velocities are not significant early in the simulation. Therefore, collisions among ice crystals are rare, resulting in small amounts of ice aggregates. As soon as ice crystals grow larger and have broadened the size spectrum later on, aggregation becomes significant and produces more ice aggregates. During the latter half of the simulation, it is obvious that the lowest $800 \mathrm{~m}$ of the deepening cloud layer contain mostly ice aggregates.

The profiles of solar heating are plotted in Fig. 5a. The solar heating rate is a sensitive function of ice water content and number concentration. In general, the solar heating becomes stronger as the ice water content and number concentration increase. The solar heating rate gradually increases upward from cloud base to a maximum slightly below the cloud top, then decreases sharply from there to the cloud top. Clearly, the solar heating is most pronounced high in the cloud layer.

The profiles of the IR heating, shown in Fig. 5b, change dramatically with time. The IR heating rate is significant throughout the cloud layer, and it is very sensitive to the content of the cloud. In general, its profiles show warming in the lower part of the cloud and cooling in the upper part. Consequently, there is differential heating within the cloud deck, because the cirrus in this case is optically thick enough that most of 

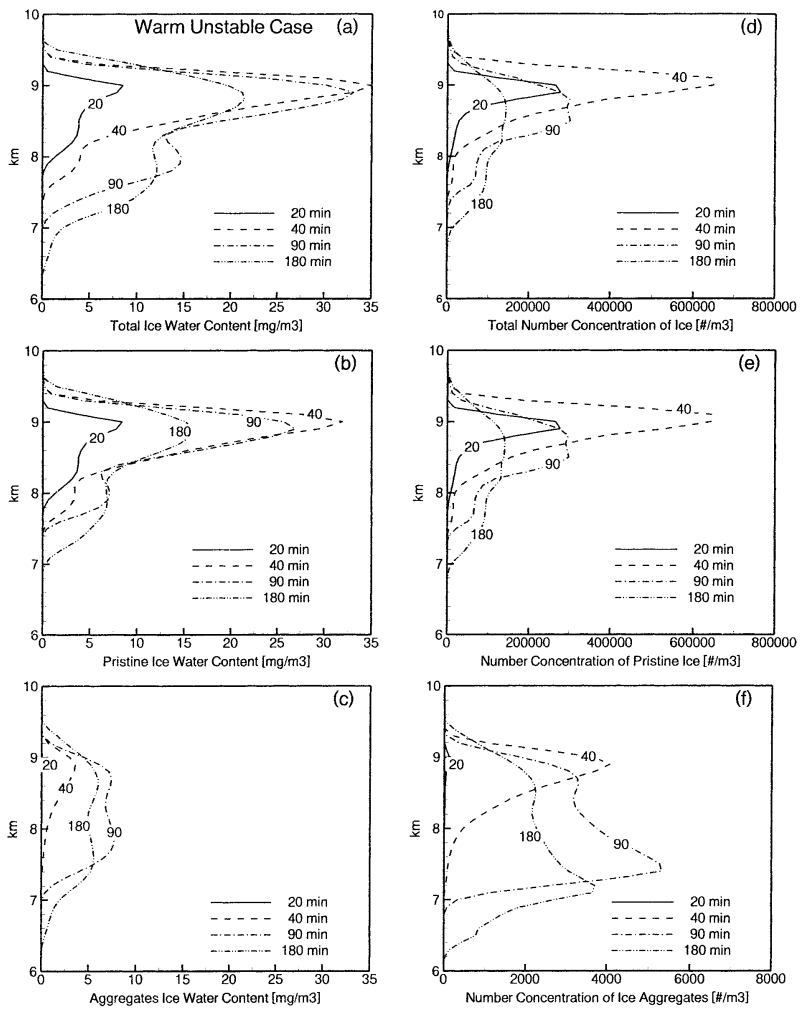

FIG. 4. Profiles of horizontally averaged ice water content and number concentration of ice, for warm unstable case. (a) Total ice water content, (b) pristine ice water content, and (c) aggregates ice water content. (d) Total number concentration of ice, (e) number concentration of pristine ice, and (f) number concentration of ice aggregates.

the radiation from below is absorbed before it reaches the cloud top. Thus, the IR warming decreases with height and eventually becomes cooling. This differential IR heating is the strongest at around $40 \mathrm{~min}$. As the profiles of ice water content and number concentration change with time, the main radiative cooling and warming layers also evolve accordingly. The magnitude of the maximum IR warming decreases as the IR warming maximum moves downward after $40 \mathrm{~min}$. In contrast to the maximum warming in the lower cloud layer, the upper maximum IR cooling does not change its elevation significantly, yet undergoes obvious change in magnitude. This implies that the radiation-induced upward motion is reduced as ice crystals fall out of the initial supersaturated layer.

During the later stages of cloud development, the peak IR warming in the lower part of the cloud wanes but the peak IR cooling in the upper part remains strong, as the solar heating systematically decreases with time. The latent heat absorption due to sublimation is most pronounced just above cloud base, and its magnitude exceeds the radiative heating rate there, so that the diabatic warming near cloud base is replaced by diabatic cooling during this stage. There is still diabatic warming in the middle of the cloud, but it becomes much weaker,
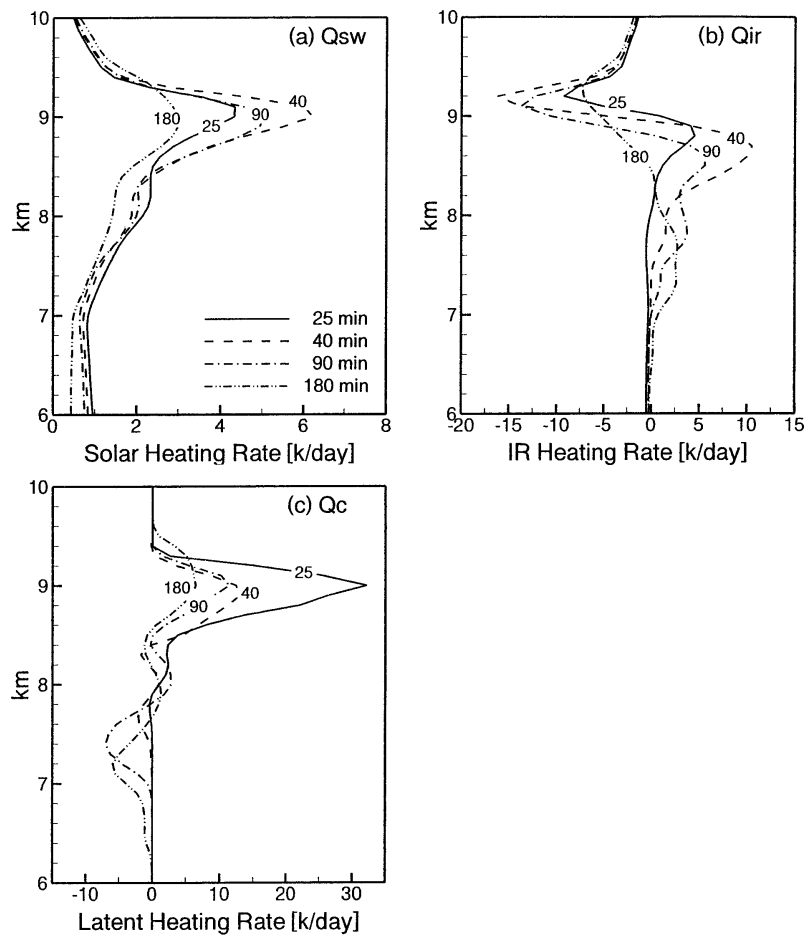

FIG. 5. Profiles of horizontally averaged (a) solar radiative heating rates $Q_{\mathrm{sw}}$, (b) IR heating rates $Q_{\mathrm{ir}}$, and (c) latent heating rates $Q_{c}$ for warm unstable case.

while the diabatic cooling near the cloud top becomes smaller. The profile of latent heating indicates that heterogeneous nucleation and diffusional growth still take place near the cloud top, and that the upper part of the cloud layer remains quite moist by the end of the simulation. This is confirmed by the profiles of relative humidity with respect to ice in Fig. 6, which also shows the profiles of the root-mean-square (rms) vertical velocity and water vapor flux. The water vapor flux increases gradually up to about $8.5 \mathrm{~km}$, and then decreases toward the cloud top, indicating flux divergence in the lower part of the cloud and convergence in the upper part. That further indicates that the water vapor is transported upward and accumulates near the cloud top, as can also be understood by considering the vertical eddy transport moisture budget equation

$$
\frac{\partial \overline{q_{v}}}{\partial t}=\cdots-\frac{\partial}{\partial z}\left(\overline{w^{\prime \prime} q_{v}^{\prime \prime}}\right)
$$

which indicates that the water vapor tends to increase (or decrease) with time if water vapor flux decreases (or increases) with height. This upward transport of water vapor causes the layer to remain moist near the cloud top.

Figure 6 also shows the vertical profiles of equivalent potential temperature. Its variation with time is the result of the combined diabatic and adiabatic heating/cooling. The cloud layer is warmed due to diabatic heating during the early stage, and is mostly stabilized except near the 

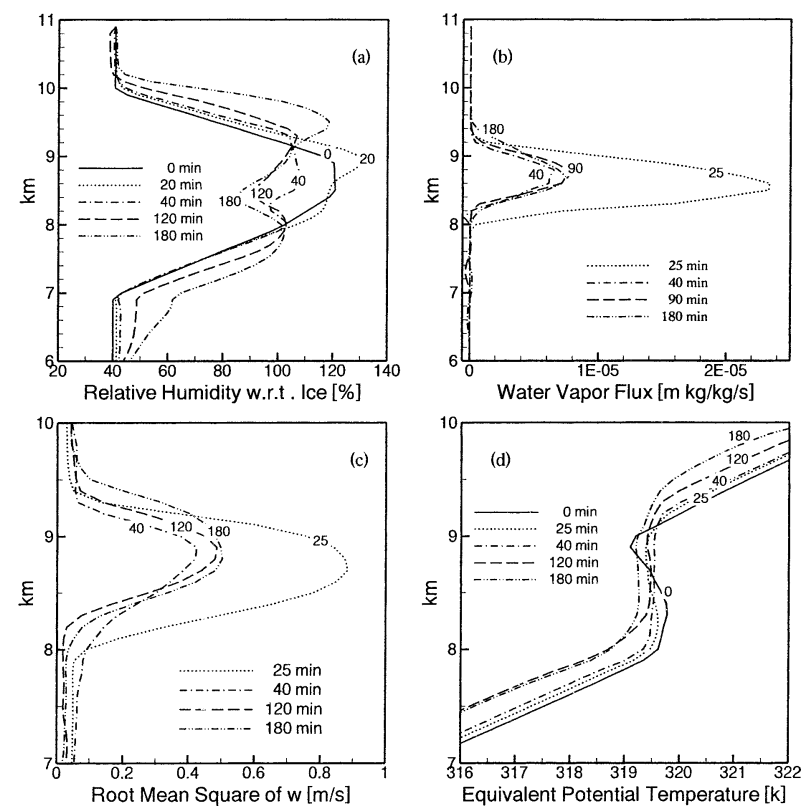

FIG. 6. Profiles of horizontally averaged (a) relative humidity with respect to ice, (b) water vapor, (c) rms vertical velocity, and (d) equivalent potential temperature for warm unstable case. Solid black curves represent the initial profiles.

cloud top. The horizontally averaged rms vertical velocity at $25 \mathrm{~min}$ is as large as $0.85 \mathrm{~m} \mathrm{~s}^{-1}$ in response to the initial vertical thermodynamic structure and random temperature perturbations. The maximum vertical velocity later drops to about $0.4 \mathrm{~m} \mathrm{~s}^{-1}$ near cloud top, owing to the slight destabilization from diabatic heating near the cloud top in the profile of equivalent potential temperature.

The domain-averaged ice water content and ice number concentration versus time for the warm unstable case are plotted in Fig. 7a. Both increase rapidly during the first $35 \mathrm{~min}$ in response to the randomly perturbed initial temperature and rapid homogeneous nucleation. The domain-averaged number concentration peaks at $35 \mathrm{~min}$ and then decreases to $63 \%$ of its maximum value by the end of the simulation. Although new ice crystals are still produced through heterogeneous nucleation after the homogeneous nucleation terminates, the domain-averaged number concentration continues to decrease due to sublimation in the lower cloud layers, indicating that the production rate of ice crystals is smaller than the consumption (sublimation) rate late in the simulation.

\section{2) Cold unstable case}

The profiles of number concentration and water content for total ice, pristine ice, and ice aggregates in the cold unstable case are plotted in Fig. 8. Many ice crystals are produced high in the cloud during the first 30 min by rapid homogeneous nucleation, which occurs from $13.7 \mathrm{~min}$ to around $33 \mathrm{~min}$, and is activated again during the last $5 \mathrm{~min}$ of the simulation. The number
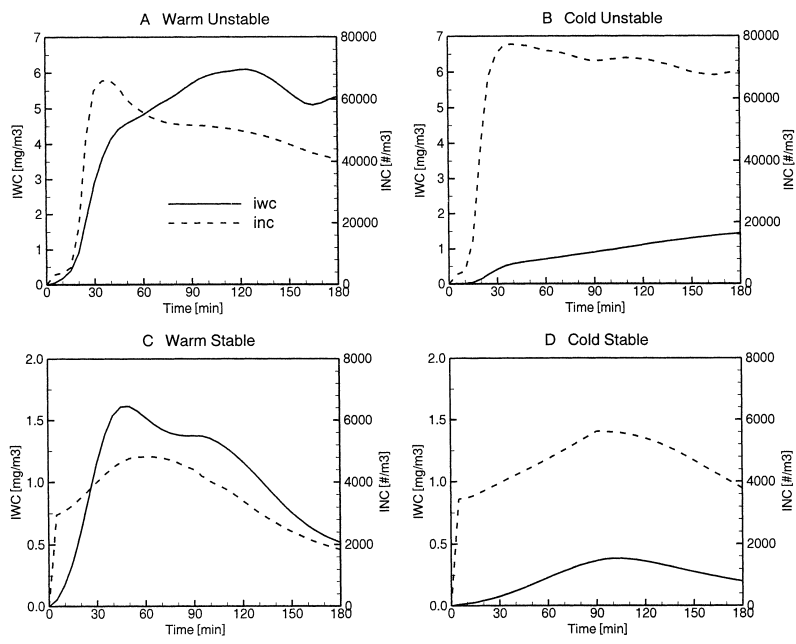

FIG. 7. Domain-averaged ice water content and ice number concentration for (a) warm unstable case, (b) cold unstable case, (c) warm stable case, and (d) cold stable case.

concentration generally increases from the cloud base to the middle of the cloud and then decreases toward the cloud top, and reaches its peak value near $13.8 \mathrm{~km}$ at about $30 \mathrm{~min}$. Although the number concentration of ice subsequently begins to decay, the rate of decay is much slower than in the warm unstable case. In addition, the level of the maximum concentration remains in the initial supersaturated layer at the end of the simulation.

The behavior of the ice number concentration may be the result of two processes. First, heterogeneous nucleation is very active high in the cloud after the 30min period of rapid growth, because the slower growth rate of ice at cold temperatures consumes less water vapor and thus allows more new ice crystals to be nucleated. Second, the growth rates of ice crystals in such cold temperatures are very small, so that the crystals remain small as well. The maximum horizontally averaged sizes of pristine ice and aggregates are 20 and $100 \mu \mathrm{m}$, respectively, meaning their fall velocities are also small. Consequently, there is still a significant amount of ice in the initial supersaturated layer at the end of the simulation. Although the ice number concentration starts to decay after $30 \mathrm{~min}$, the maximum ice water content keep increasing until about $150 \mathrm{~min}$. This is because new ice is produced near the cloud top at all times and the rate of ice crystal fallout is not significant due to the small crystal size, so most of the ice can continue to grow in the supersaturated layer.

The profiles of number concentration and water content for ice aggregates are also shown in Fig. 8. Both at any given location are much smaller than for pristine ice during the simulation, and suggest that ice aggregates are concentrated in the lower part of the cloud layer by the end of the simulation. The lowest $600 \mathrm{~m}$ of the cloud contains mostly ice aggregates.

The solar heating profiles are shown in Fig. 9a. In general, the solar heating rate gradually increases up- 

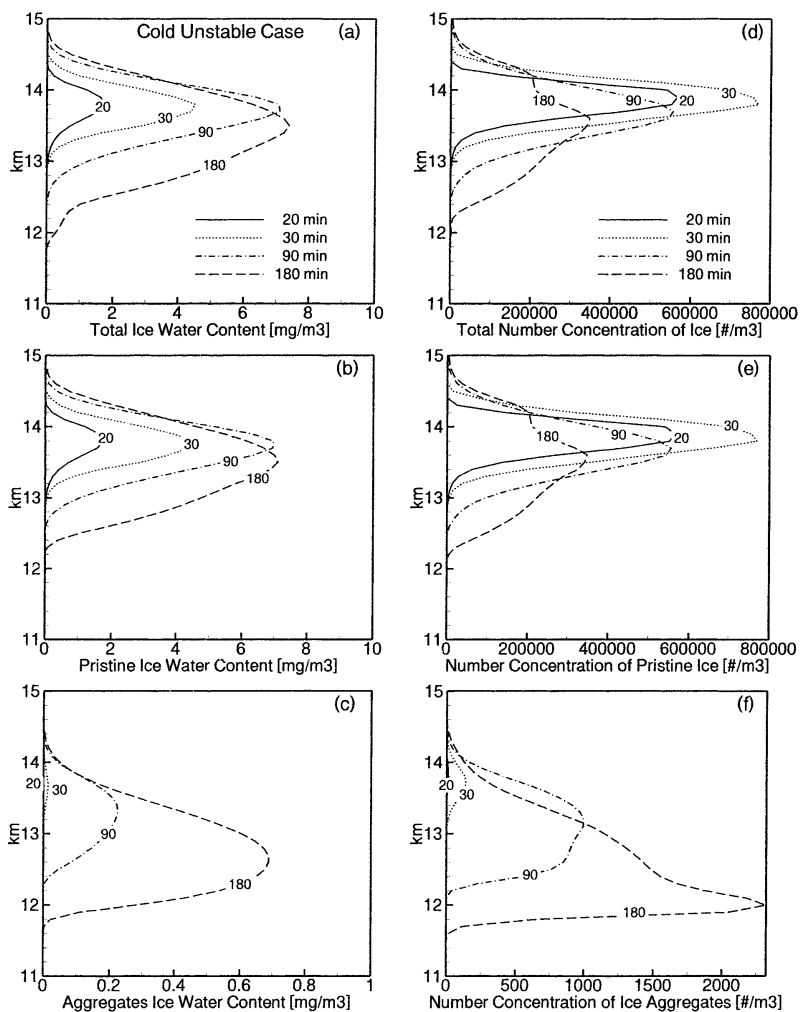

FIG. 8. Profiles of horizontally averaged ice water content and number concentration of ice for cold unstable case. (a) Total ice water content, (b) pristine ice water content, and (c) aggregates ice water content. (d) Total number concentration of ice, (e) number concentration of pristine ice, and (f) number concentration of ice aggregates.

ward from the cloud base to slightly below the cloud top, and then decreases sharply up to the cloud top. It is apparently sensitive to the number concentration profile, reaches a maximum around $30 \mathrm{~min}$, and is concentrated in the upper cloud layer.

The IR heating profiles, shown in Fig. 9b, change dramatically with time. The IR heating increases upward to a maximum value near $13.5 \mathrm{~km}$ and then decreases toward the cloud top. The IR cooling at the cloud top is negligible, whereas the IR warming is significant throughout the whole cloud layer. This is because the simulated cirrus is optically thin, so that the radiation from the lower and warmer layer can penetrate to the cloud top. Thus, the cloud layer is radiatively warmed during the simulation. The IR warming rates in the cloud layer are much larger than the solar warming rates, reaching as much as $40^{\circ} \mathrm{C}$ day $^{-1}$.

The profiles of latent heating rates, shown in Fig. 9c, have much smaller amplitudes than the IR heating rates. This is caused by the small particle growth rates at cold temperatures. Subcloud sublimation is insignificant until $90 \mathrm{~min}$ into the simulation. The latent and solar heating rates are also much smaller than the IR heating rate throughout the simulation. The solar heating is smaller
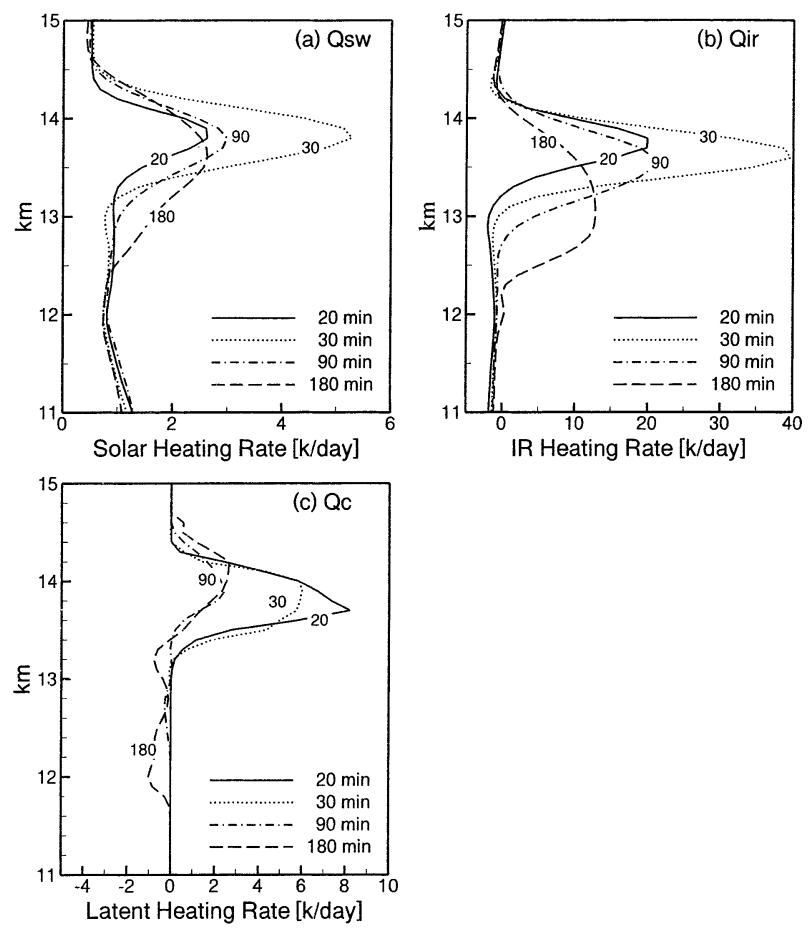

FIG. 9. Profiles of horizontally averaged (a) solar radiative heating rates $Q_{\text {sw }}$, (b) IR heating rates $Q_{\text {ir }}$, and (c) latent heating rates $Q_{c}$, for cold unstable case.

than the latent heating rate until $20 \mathrm{~min}$, but by $30 \mathrm{~min}$ the two become comparable.

The profile of latent heating at $180 \mathrm{~min}$ indicates that ice nucleation and diffusional growth processes still take place near the cloud top (Fig. 9c), and also implies that the upper part of the cloud remains quite moist at the end of the simulation. This is confirmed by the profiles of relative humidity with respect to ice, shown in Fig. 10a. The water vapor flux profiles are shown in Fig. $10 \mathrm{~b}$. The water vapor flux increases gradually up to the middle of the cirrus layer and then decreases toward the cloud top, implying flux divergence in the lower part of the cloud and flux convergence in the upper part. This indicates that the water vapor is transported upward and accumulates near the cloud top, clarifying why the layer remains moist there. This may also explain why homogeneous nucleation is reactivated again during the last $5 \mathrm{~min}$ of the simulation.

The profiles of the horizontally averaged root-meansquare vertical velocity and equivalent potential temperature are shown in Figs. 10c and 10d, respectively. The time variation of equivalent potential temperature is determined by the combined effects of diabatic heating/cooling and adiabatic cooling. It can be seen that the cloud layer undergoes strong diabatic heating; at the end of the simulation, this diabatic heating is about 14 $\mathrm{K} \mathrm{day}^{-1}$. Most of the cloud deck is stabilized, except near the cloud top. The root-mean-square vertical velocity is as large as $1.2 \mathrm{~m} \mathrm{~s}^{-1}$ at $30 \mathrm{~min}$ in response to 

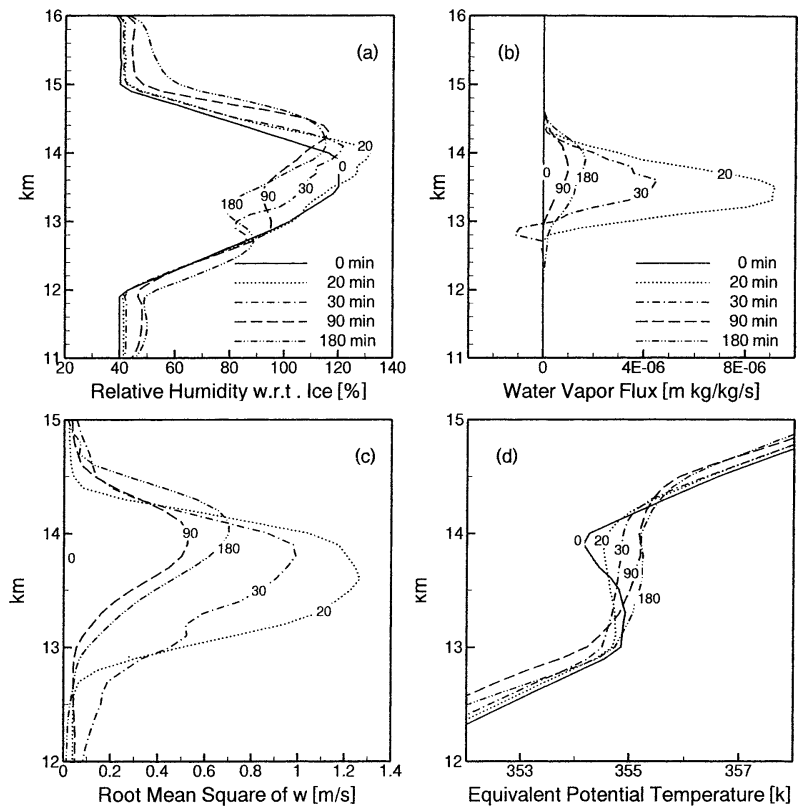

FIG. 10. Profiles of horizontally averaged (a) relative humidity with respect to ice, (b) water vapor, (c) rms vertical velocity, and (d) equivalent potential temperature for cold unstable case. Solid black curves represent the initial profiles.

the initial ambient vertical thermal structure and random temperature perturbations. Late in the simulation, the maximum vertical velocity is about $0.6 \mathrm{~m} \mathrm{~s}^{-1}$ and is concentrated near cloud top. This may be explained by the destabilizing effect of diabatic heating near the cloud top as shown in the profile of equivalent potential temperature.

The domain-averaged ice water content and ice number concentration as functions of height at different times (Fig. 7b) both increase rapidly during the first 30 min in response to the randomly perturbed temperature and homogeneous nucleation. The ice concentration is quasi-steady thereafter, down only $9 \%$ from its maximum at the end of the simulation, indicating that the production rate of ice crystals due to nucleation is comparable to the dissipation rate due to sublimation in the later stages. The domain-averaged ice water content increases with time during the entire simulation, due to a combination of several effects. In comparison with the warm unstable case, the slower growth rate results in smaller ice crystals, which have small terminal velocities and tend to stay in the original supersaturated layer longer. Those ice crystals that do fall out to lower drier layers sublimate very slowly due to the low temperature. Finally, both homogeneous and heterogeneous nucleation processes are active throughout most of the simulation.

\section{3) WARM STABLE CASE}

A special feature of the model results in the warm stable case, as contrasted to the two unstable cases be-
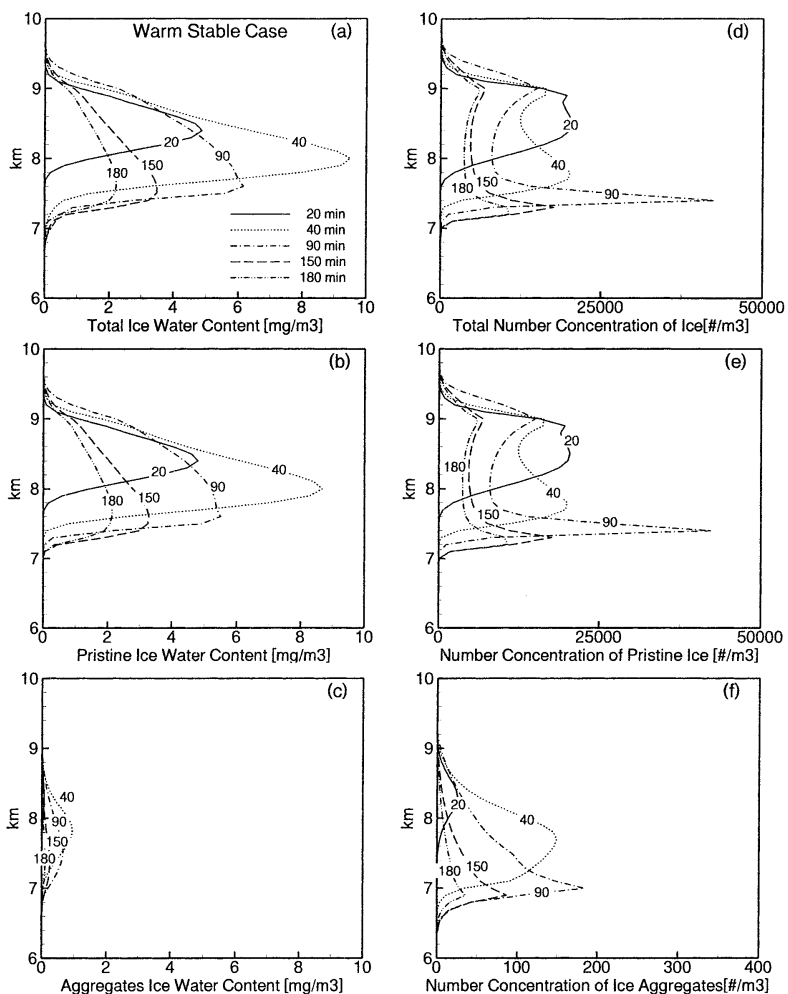

Fig. 11. Profiles of horizontal averaged ice water content and number concentration of ice for warm stable case. (a) Total ice water content, (b) pristine ice water content, and (c) aggregates ice water content. (d) Total number concentration of ice, (e) number concentration of pristine ice, and (f) number concentration of ice aggregates.

fore, is that no homogeneous nucleation takes place. This is mainly due to the stable initial structure that limits the vertical motion and hence the cloud development and vertical transport of water vapor available for the ice crystal growth. Therefore, the cloud is not sufficiently cold or moist to favor homogeneous nucleation. As a result, the only source of ice crystals for this stable case comes from heterogeneous nucleation, which produces much fewer ice crystals than homogeneous nucleation. The profiles of horizontally averaged ice water content and number concentration are shown in Fig. 11. The ice water content generally increases from the cloud base upward to a maximum value in midcloud and then decreases toward the cloud top. The location of maximum ice water content moves rapidly downward with time due to sedimentation during the first $40 \mathrm{~min}$ of the simulation.

During the early stages, the number concentration of ice is fairly uniform within the initial supersaturated layer. This is because the initial relative humidity with respect to ice is uniform and only heterogeneous nucleation, which depends solely on relative humidity, is involved. However, the profile of number concentration changes dramatically at later stages, as the ice crystals seem to concentrate in the drier lower part of the cloud. Because ice crystals have grown larger by the time they 

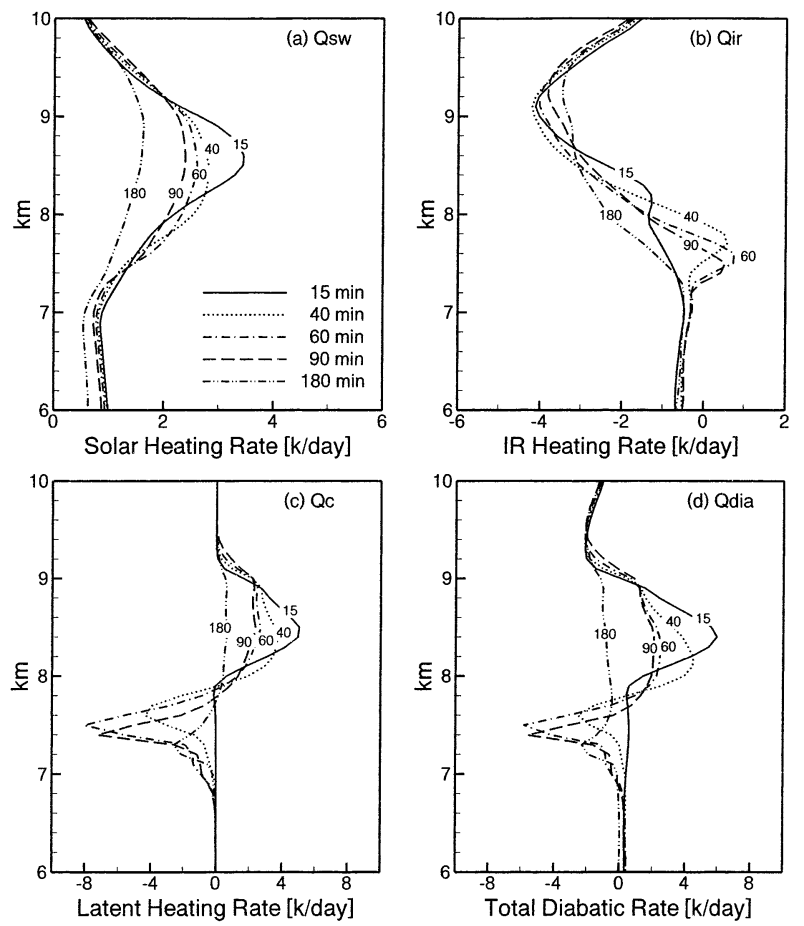

FIG. 12. Profiles of horizontally averaged (a) solar radiative heating rate $Q_{\text {sw }}$, (b) IR heating rates $Q_{\text {ir }}$, (c) latent heating rates $Q_{c}$, and (d) total diabatic heating rates $Q_{\text {dia }}$ for warm stable case.

fall into the subsaturated environment, most do not sublimate to their core size, so that the number of ice crystals does not decrease much due to sublimation beneath the cloud. Instead, the number actually increases because ice crystals sediment from the upper cloud layer to enter the lower layer. This indicates that, in the lower layer, the increase of ice crystals due to fallout from the upper layer exceeds the number of crystals lost due to sublimation.

The profiles of the solar, IR, and latent heating rates are shown in Fig. 12. The magnitudes of these diabatic heating rates are comparable. The IR heating rate (Fig. 12b) shows weak warming near the cloud base and strong cooling near the cloud top. The profiles of latent heating rates (Fig. 12c) indicate that ice crystal fallout is significant after $40 \mathrm{~min}$. The total diabatic heating rates (Fig. 12d) show warming near the cloud base and cooling near the cloud top after $40 \mathrm{~min}$. In this simulation, the diabatic heating does not make the cloud layer unstable.

The domain-averaged ice water content and number concentration (Fig. 7c) both increase rapidly during the first $40 \mathrm{~min}$ in response to the randomly perturbed initial temperature. Since there is no homogeneous nucleation to compete for water vapor, ice crystals grow sufficiently large to fall into the lower subsaturated layer and sublimate. Therefore, the domain-averaged ice crystal concentration decreases after $40 \mathrm{~min}$. The concurrent de-
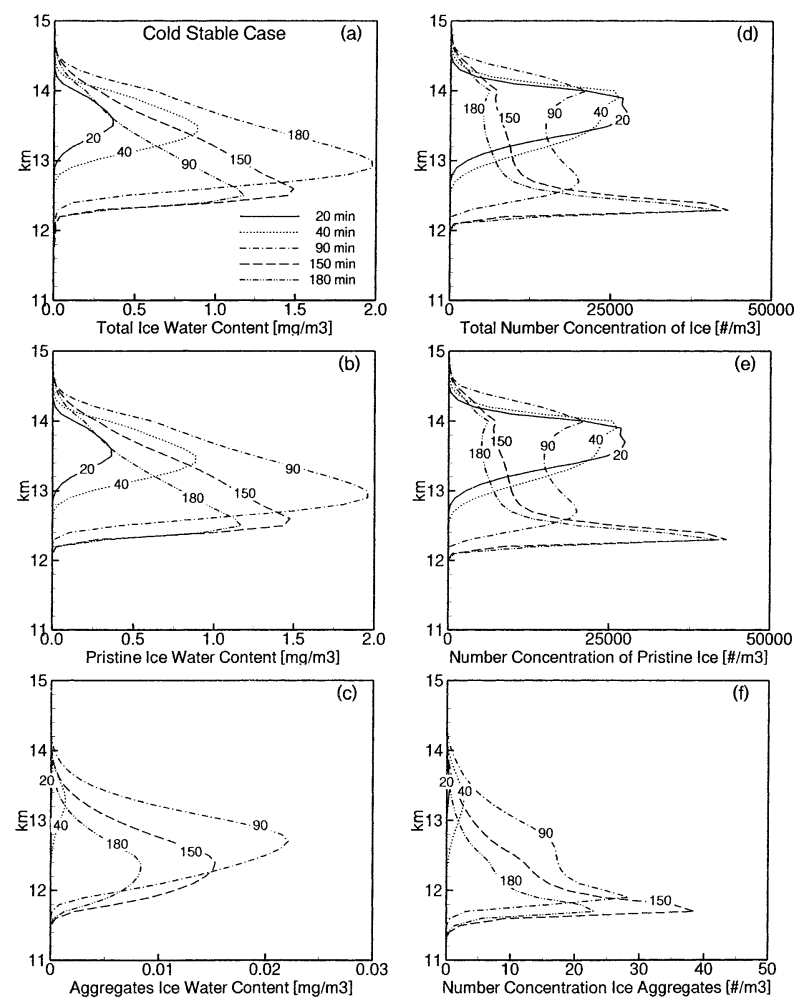

FIG. 13. Profiles of horizontally averaged ice water content and number concentration of ice for cold stable case. (a) Total ice water content, (b) pristine ice water content, and (c) aggregates ice water content. (d) Total number concentration of ice, (e) number concentration of pristine ice, and (f) number concentration of ice aggregates.

crease of ice water content can be explained in similar fashion.

\section{4) Cold stable case}

Just as in the warm stable case, homogeneous nucleation does not occur in the cold stable case. The shapes of the ice water content and number concentration profiles are very similar to those for the warm stable case, but the time variations of those profiles are very different (Fig. 13), largely due to the altered growth rates at colder temperatures. These growth rates are very small, so that the ice crystals remain small and stay in the initially supersaturated layer longer. As soon as they grow to sizes with significant terminal velocities, they fall out of this layer. But since it takes more time for those ice crystals to grow in the supersaturated layer, the amplitude of the ice water content profile does not peak until $90 \mathrm{~min}$.

The profiles of solar, IR, and latent heating rates are shown in Fig. 14. Both solar heating (Fig. 14a) and IR heating (Fig. 14b) are very sensitive to the cloud ice content. They are largest around $70 \mathrm{~min}$ into the simulation. The profiles of IR heating show warming at the cloud base, and the IR cooling are distributed throughout most of the cloud deck due to its small optical depth. 

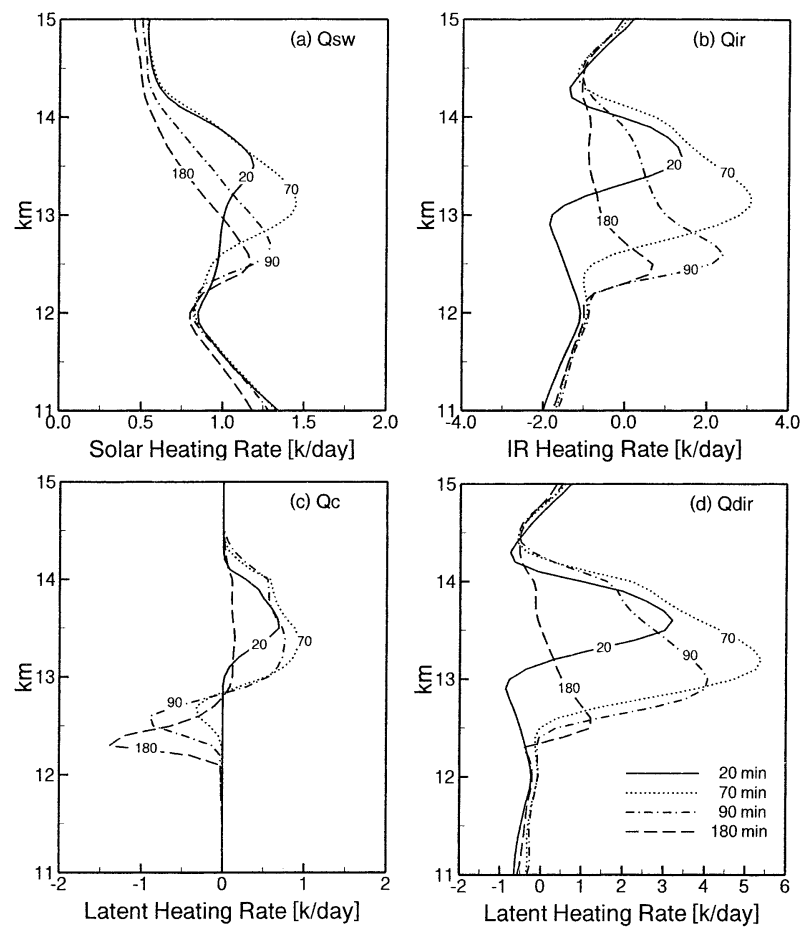

FIG. 14. Profiles of horizontally averaged (a) solar radiative heating rates $Q_{\text {sw }}$, (b) IR heating rates $Q_{\text {ir }}$, (c) latent heating rates $Q_{c}$, and (d) total diabatic heating rates $Q_{\mathrm{dia}}$ for cold stable case.

The warming effect is decreasing upward, and eventually there is very weak cooling near the cloud top. The profiles of latent heating (Fig. 14c) reveal that the ice crystal fallout is not significant until $70 \mathrm{~min}$. The total diabatic heating rates (Fig. 14d) show a dominance of IR heating within the cloud layer. The cooling due to sublimation in the lower part of the cloud is balanced by solar and IR warming. The diabatic heating does not destabilize the cloud layer during the simulation, and its effect does not exceed that of adiabatic cooling in this case.

The domain-averaged content and number concentration of ice are shown in Fig. 7d. Both quantities reach their maxima about 90 min into the simulation, and then decay due to sublimation of ice.

It may useful to point out that the typical updraft produced by the cloud development is around $40 \mathrm{~cm}$ $\mathrm{s}^{-1}$, far exceeding the $3 \mathrm{~cm} \mathrm{~s}^{-1}$ imposed in the background. Thus the importance of background updraft is rather secondary to the above discussions.

\section{b. Simulation set II: Effect of radiation on the life cycle of cirrus}

The purpose of this simulation set is to gauge the influence of radiation on the life cycle of cirrus. Since the previous simulation set has shown that radiative heating is not significant for stable cases, we only consider warm and cold unstable environments in the cur- rent simulation set. To understand how sensitive the development of cirrus is to radiation, we consider both daytime and nighttime conditions as well as a case in which all radiative processes are turned off. Since we examine all three possibilities for both warm and cold cirrus, there are a total of six cases in this simulation set, as summarized in Table 2. The ice habit considered here is columnar, with a background updraft of $3 \mathrm{~cm}$ $\mathrm{s}^{-1}$ imposed at all times during each simulation.

\section{1) WARM CIRRUS}

We find that the thermodynamic structure of the warm cloud changes according to the scenario for diabatic heating. The profiles of horizontally averaged rms vertical velocity and equivalent potential temperature are shown in the left two columns of Fig. 15. The latter profiles indicate that for all three cases the cloud layer is destabilized high up but stabilized elsewhere. Cases with radiative processes have relatively greater destabilization in the upper layer during the simulations, while only slight destabilization occurs there without radiative processes. Thus, radiative processes should promote convective structure, as confirmed by the profiles of the rms vertical velocity in Fig. 15. The vertical velocities in all three cases during the first $30 \mathrm{~min}$ are as large as $0.8 \mathrm{~m} \mathrm{~s}^{-1}$ in response to the initial thermodynamic environment structure and randomly imposed temperature perturbations. The vertical velocity then decreases following the period of rapid consumption of available energy. However, whereas turning off all radiative processes brings a large reduction of the vertical velocity in the cloud layer at the end of the simulation, this reduction is much less for the cases with active radiation processes. The vertical velocity is slightly larger in daytime cirrus than at night, since the upper layer is destabilized slightly more in the daytime case.

The horizontally averaged water vapor flux and relative humidity with respect to ice are plotted in the right two columns of Fig. 15. The water vapor flux increases upward from the cloud base to midlayer and then decreases toward the cloud top, implying flux divergence in the lower part of the cloud and convergence in the upper part. This vertical transport of water vapor is slightly larger with radiative processes than without. The differences in the vertical transports result in different vertical distributions of water vapor in the cloud layer. Since the upward transport of water vapor is less without radiation, the middle part of the cloud layer remains moister than in the cases with radiative processes, particularly near $9.5 \mathrm{~km}$.

The profiles of horizontally averaged ice number concentration and ice water content are shown in Fig. 16 for warm cirrus. Overall, the cirrus decays more quickly without radiative processes. These radiative processes do not affect homogeneous nucleation, which starts at about 14 min and ends around $39 \mathrm{~min}$ in all three cases. 

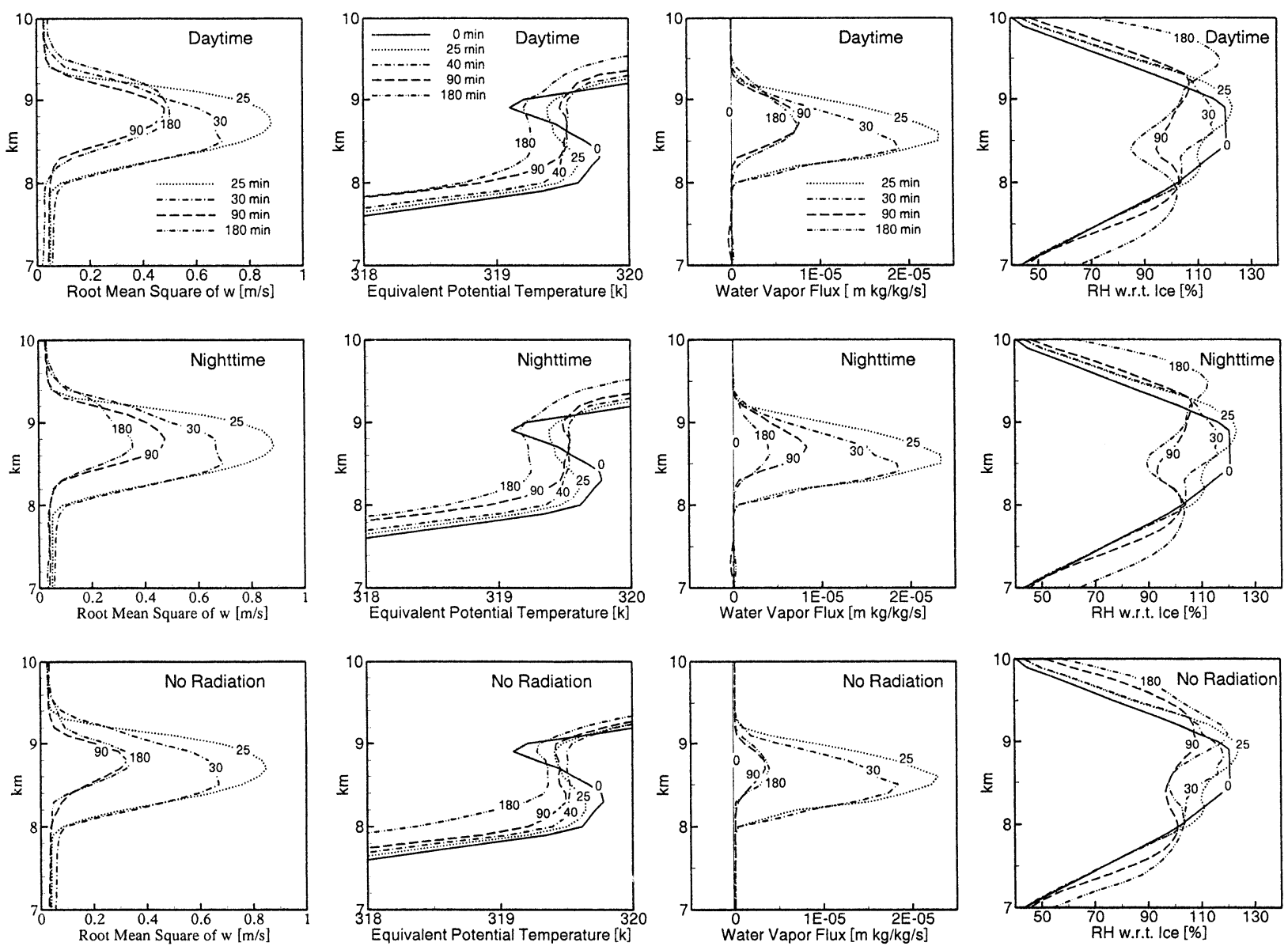

FIG. 15. Warm unstable case. Profiles of horizontally averaged rms vertical velocity, equivalent potential temperature, water vapor flux, and relative humidity with respect of ice for daytime, nighttime, and no radiation.
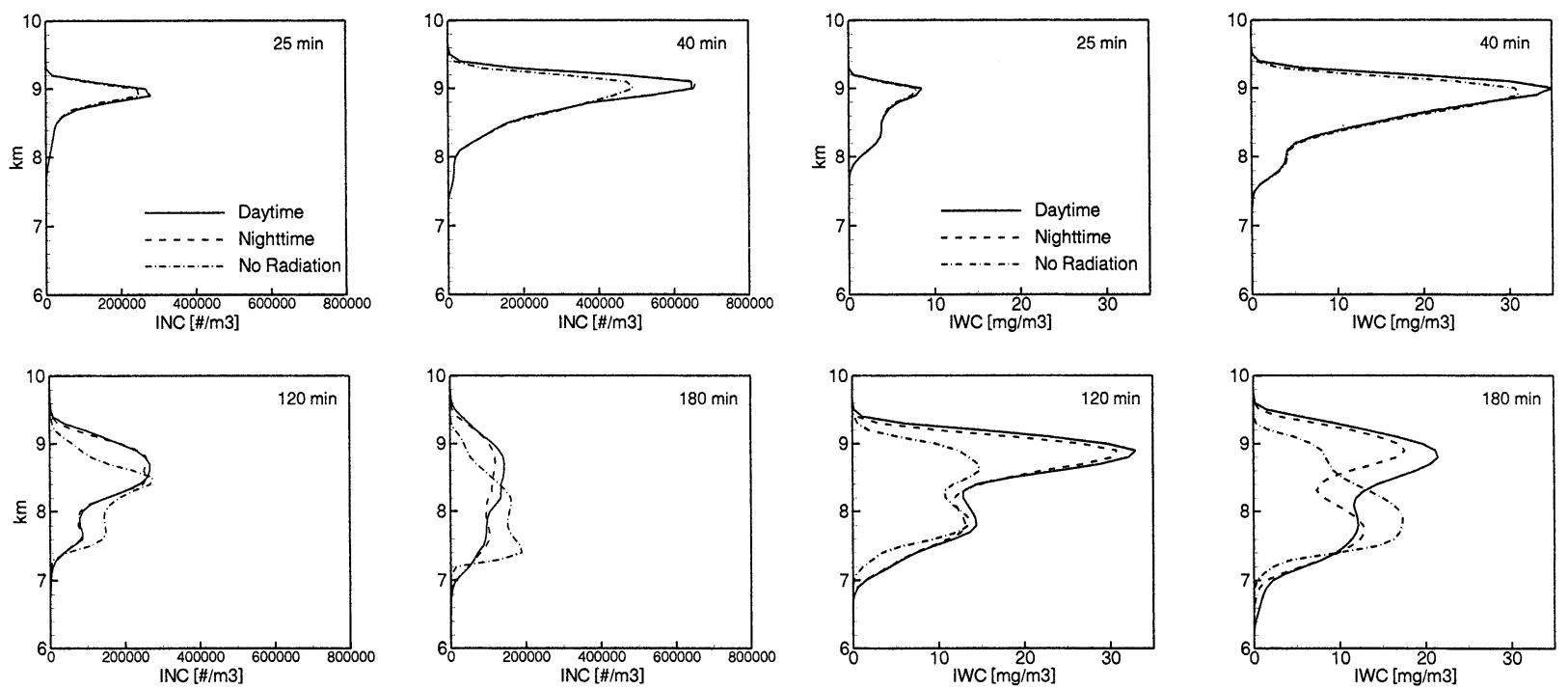

FIG. 16. Warm unstable case. (left two columns) Profiles of horizontally averaged number concentration of ice and (right two columns) ice water content for daytime, nighttime, and condition without radiation. 

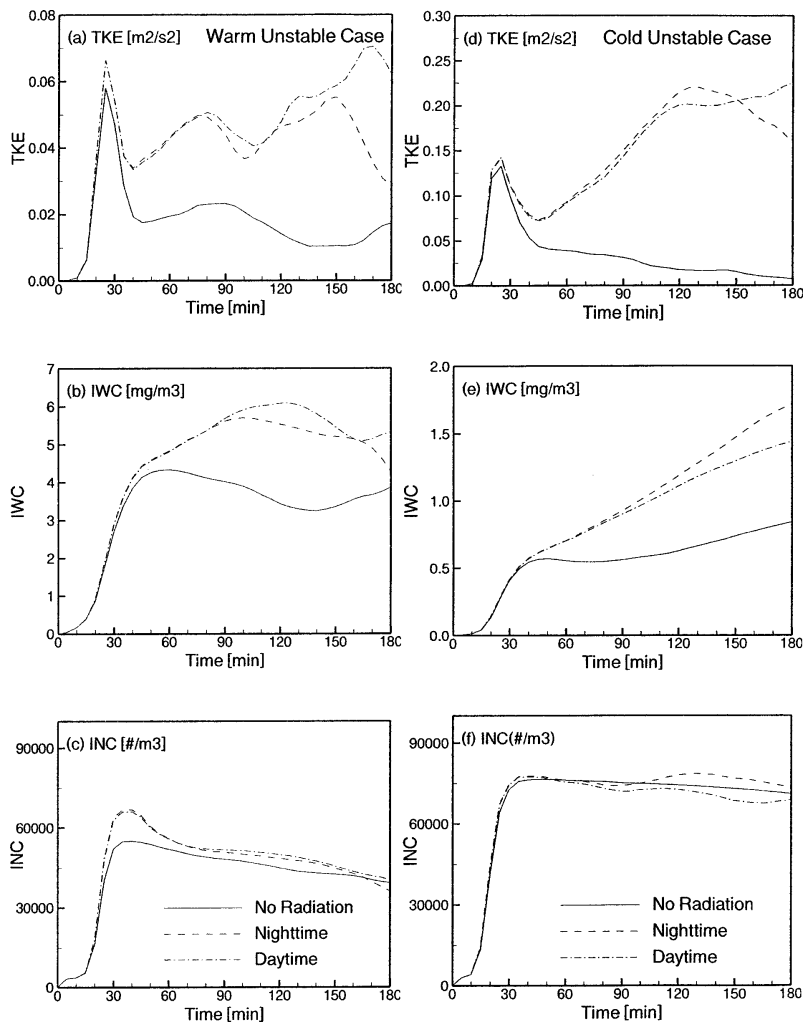

FIG. 17. Domain-averaged turbulent kinetic energy, total ice water content, ice number concentration for daytime, nighttime, and no radiation. (left) The warm unstable case, and (right) the cold unstable case.

Thus, the differences among these profiles in the three cases are insignificant during the first $25 \mathrm{~min}$. The number concentration of ice is slightly less without radiation, as is the vertical motion during the growth period. The differences among the three cases become greater during the later stages. The daytime cirrus then has higher ice water content than the nighttime cirrus because it is more convective. It is evident that the case without radiation decays faster than the cases with radiative processes, at least above $8.5 \mathrm{~km}$. Thus, the radiative processes tend to lengthen the life cycle of a cirrus cloud. Furthermore, the cirrus tends to persist longer by day than at night, because more ice is produced by heterogeneous nucleation from the upper cloud layer during the later stages of the simulations. The vertical extent of the cloud is greater with radiative processes than without.

The domain-averaged turbulent kinetic energy (TKE), ice number concentration, and ice water content are shown in the left panel of Fig. 17. It is seen that the cloud development is less vigorous without radiative processes. The TKE decays rapidly after most of the initially added temperature perturbations and latent energy have dissipated. On the other hand, the energy of the cloud is maintained by the radiative processes after the rapid growth period in the two cases with radiation turned on. The difference in TKE between the daytime and nighttime cirrus is very small before $90 \mathrm{~min}$ and becomes larger after that, as the TKE of daytime cirrus becomes significantly larger than that of nighttime cirrus because of more pronounced radiative destabilization. The corresponding ice water content and number concentration are also larger with radiation than without. Both are slightly larger for daytime cirrus than for nighttime cirrus.

\section{2) COLD CIRRUS}

For the cold cirrus case, the difference in destabilization by diabatic heating between the daytime and nighttime cases is small before $100 \mathrm{~min}$, with slightly larger destabilization by night. However, the destabilization is greater by day than at night in the last $30 \mathrm{~min}$, as seen in the profiles of root-mean-square vertical velocity and the equivalent potential temperature in Fig. 18. The corresponding profiles for water vapor flux and relative humidity with respect to ice are also plotted in Fig. 18.

The profiles of horizontally averaged ice number concentration, and ice water content for cold cirrus are shown in Fig. 19. The cloud is thicker with radiative processes than in their absence. The ice water content is the largest for nighttime cirrus, smallest without radiation, and intermediate for daytime cirrus.

The time series of domain-averaged TKE, ice number concentration, and ice water content are shown on the right-hand side of Fig. 17. The difference in TKE between daytime and nighttime cirrus is very small before 90 min, but subsequently becomes larger. The TKE of nighttime cirrus is the larger, except during the last 30 min. Cloud development is much less vigorous when radiative processes are turned off. The corresponding ice water content is larger with radiation than without.

The above discussions make it clear that the radiation directly affects the intensity and structure of convective elements within the cloud generation region. The vertical structure of the radiative heating modifies the static stability structure in the layer. This effect is cumulative and is thus important to the longer-term development of the cloud layer. For the warm unstable case, the daytime cloud is more energetic dynamically. However, for the cold unstable case, the nighttime cloud is more energetic.

\section{c. Simulation set III: Effect of latent heat on the development of cirrus}

The third simulation set examines the sensitivity of the cirrus development to the latent heat transfer due to sublimation and deposition. A simulation without diabatic heating is included for comparison. The conditions of the simulations are summarized in Table 2 .

The domain-averaged TKE, ice water content, and number concentration are shown in Fig. 20. It is evident 

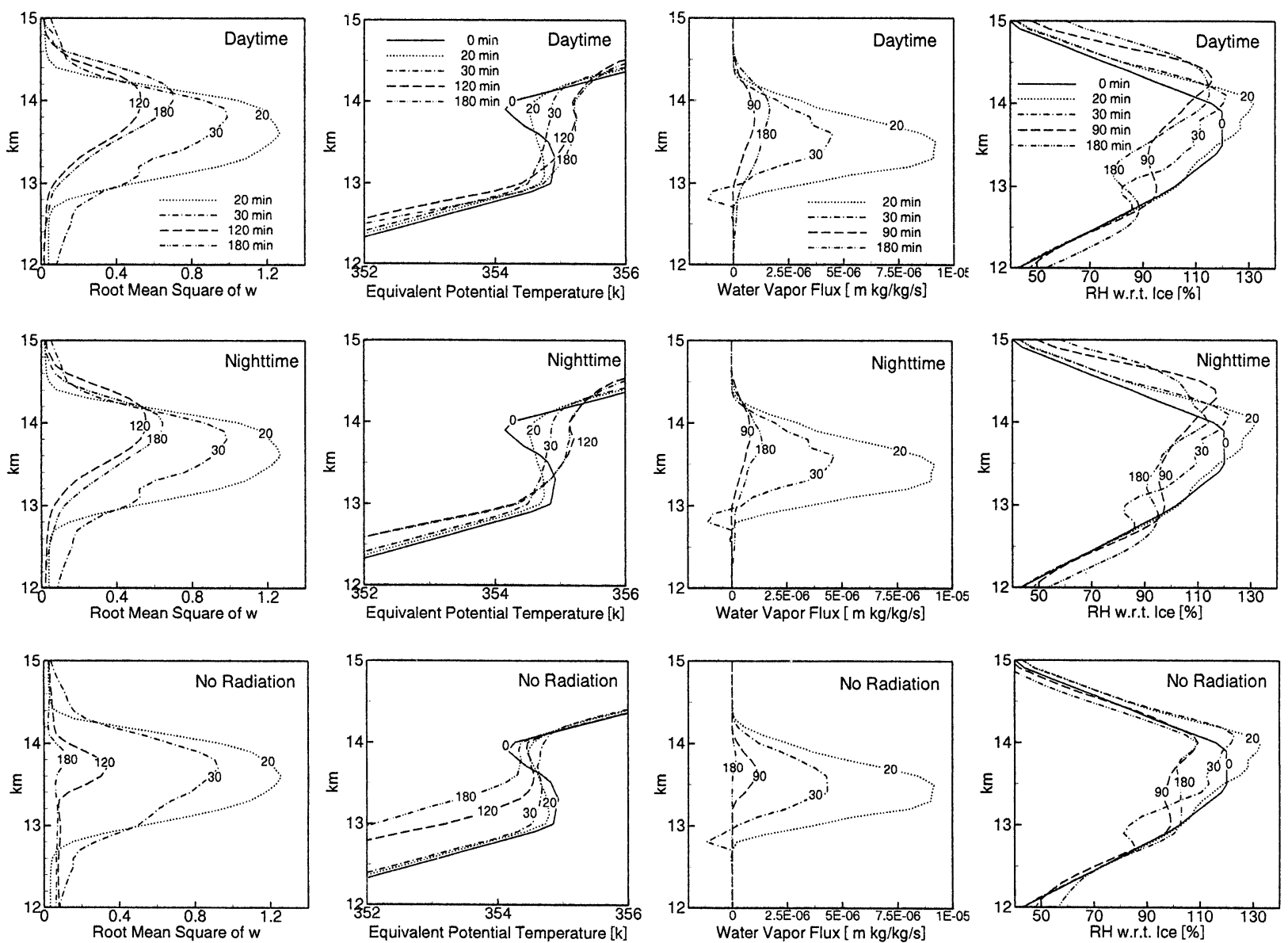

FIG. 18. Cold unstable case. Profiles of horizontally averaged rms vertical velocity, equivalent potential temperature, water vapor flux, and $\mathrm{RH}$ with respect to ice for daytime, nighttime, and condition without radiation.
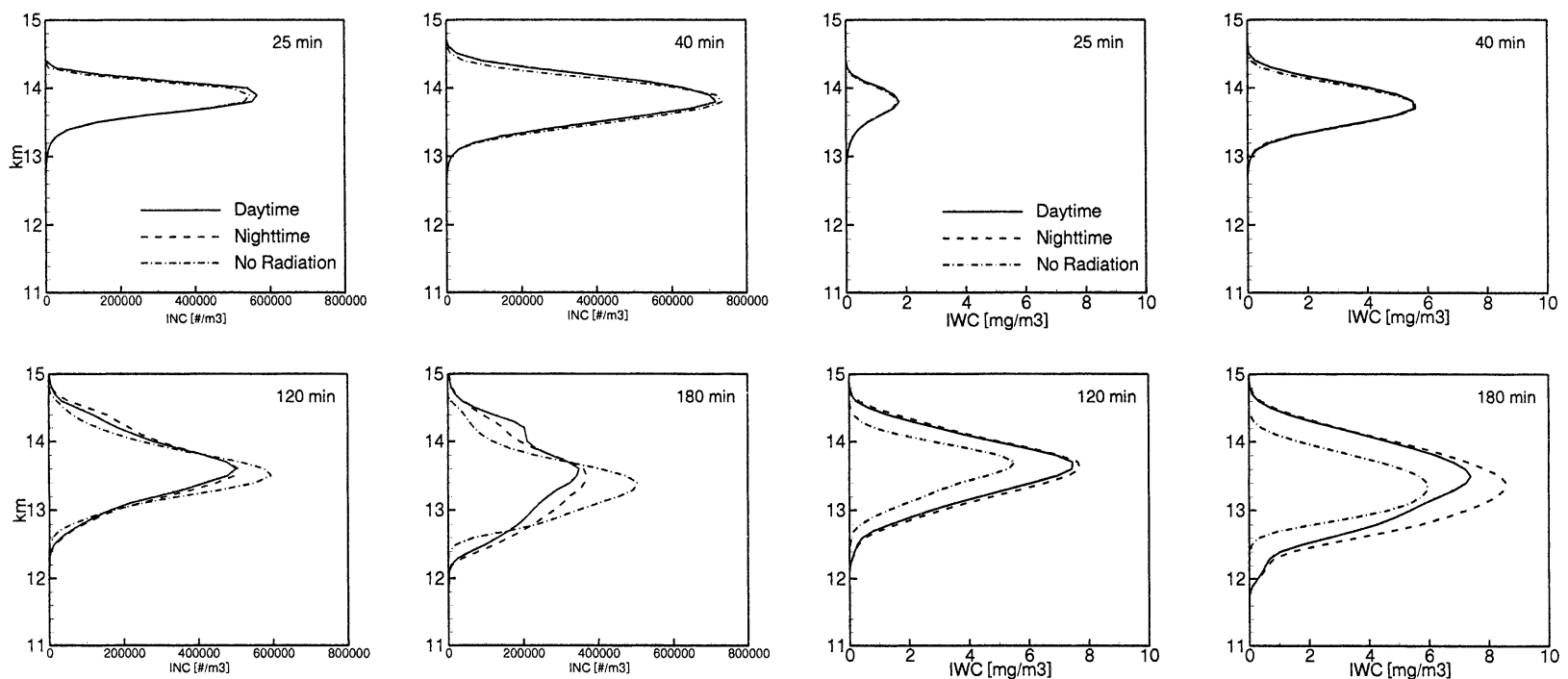

FIG. 19. Cold unstable case. (left two columns) Profiles of horizontally averaged number concentration of ice and (right two columns) ice water content for daytime, nighttime, and no radiation. 

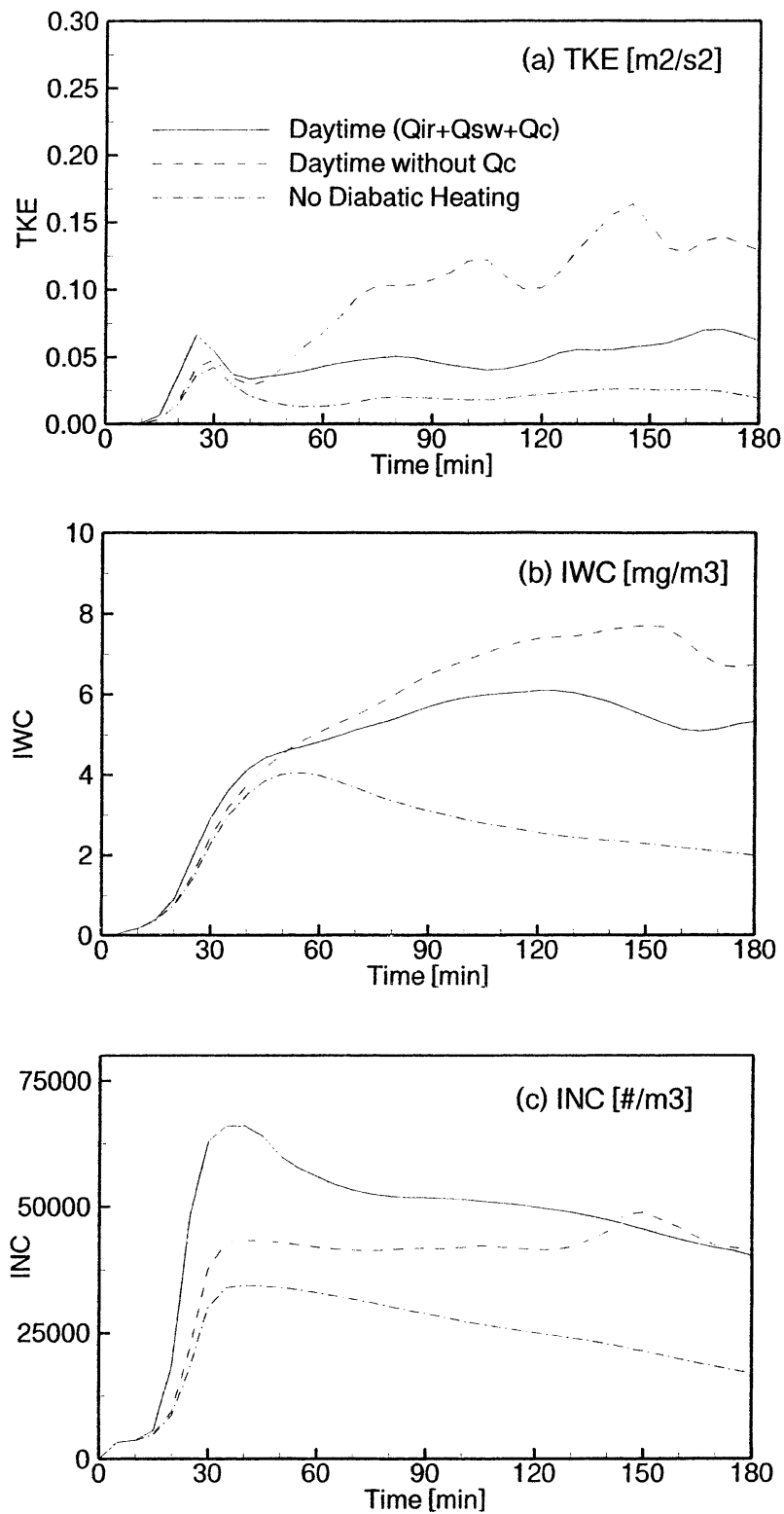

FIG. 20. Domain-averaged (a) turbulent kinetic energy, (b) total ice water content, and (c) number concentration of ice, for daytime (solid line), daytime without latent heating (dashed line), and no diabatic heating (dash-dotted line).

that the cloud intensity, as manifested by the TKE, remains weak without the help of diabatic heating. There are two types of diabatic heating: (a) radiative heating and (b) latent heating due to the deposition and sublimation of ice in the cloud. It is known from the previous section that the radiative processes both strengthen and prolong the cirrus by modifying the thermodynamic structure of the cloud layer. The latent heating, however, plays different roles during the early versus later stages of cloud development. Through $30 \mathrm{~min}$, the latent heating seems to provide energy for the initial perturbation to grow, thus providing positive feedback to the growth
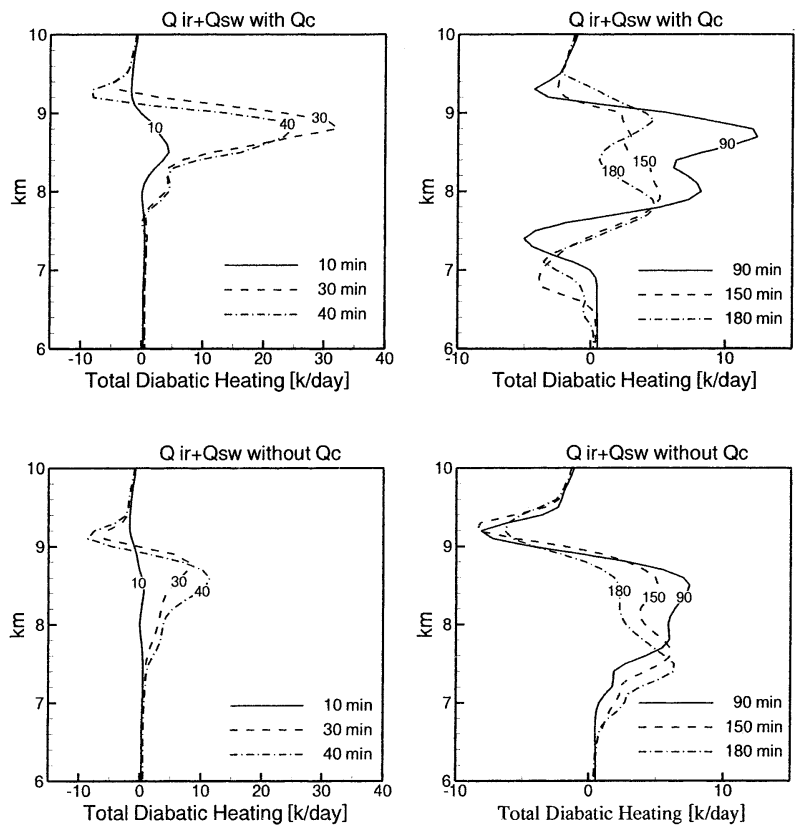

FIG. 21. Profiles of horizontally averaged diabatic heating rates. (top) Daytime with latent heating. (bottom) Daytime without latent heating.

of the cloud. It is clear in Fig. 20 that the daytime cloud is much less energetic during the early stage without latent heating than with it. Later, however, there is a reversal in the role of latent heating. Then, latent heating serves to stabilize the cloud layer, and thus provides a negative feedback to cirrus development. This negative feedback becomes more pronounced as more ice crystals fall down to the subsaturated layer and cause more sublimational cooling. During the later stage, in fact, the cloud is much more energetic without latent heating than with it. The case without any diabatic heating is the least energetic, and decays dramatically with regard to ice water content and particle count. The domain-averaged number concentration of ice is smaller with latent heating than without after $140 \mathrm{~min}$, because more ice crystals are produced during the growing stage of the cloud with latent heating. The trend of the domain-averaged ice water content roughly follows that of the domain-averaged TKE. Among the three cases, the ice water content becomes the largest for no latent heating during the later stages of the simulation.

The role of latent heating, as described above, can be seen more clearly in Fig. 21. The vertical profiles of diabatic heating at different times, with latent heating active (top of Fig. 21), reveal warming in the upper layer and cooling in the lower layer. On the other hand, the corresponding profiles without latent heating (bottom of Fig. 21) show more cooling at cloud top ( $~ 9-$ $9.5 \mathrm{~km}$ ) and warming instead of cooling below $\sim 7.5$ $\mathrm{km}$, in the last $90 \mathrm{~min}$ of the simulation. It is clear that the diabatic stabilization is less pronounced without latent heating. 

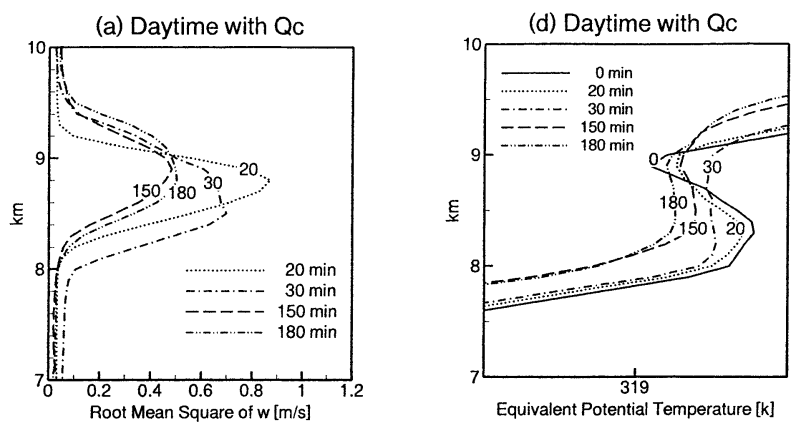

(b) Daytime without Qc
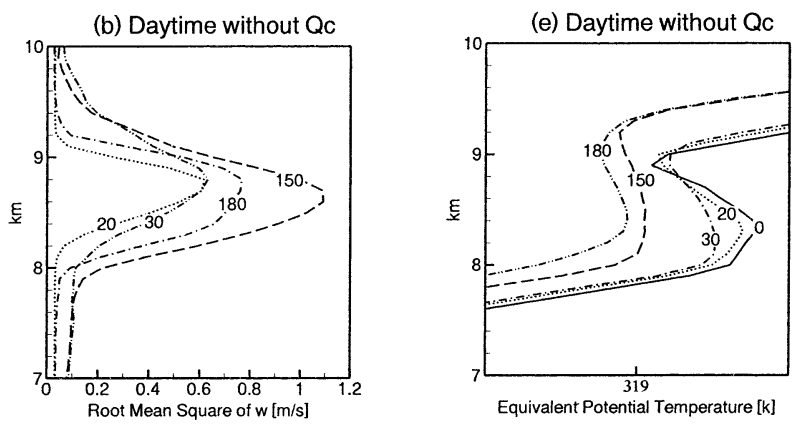

(c) No Diabatic Heating
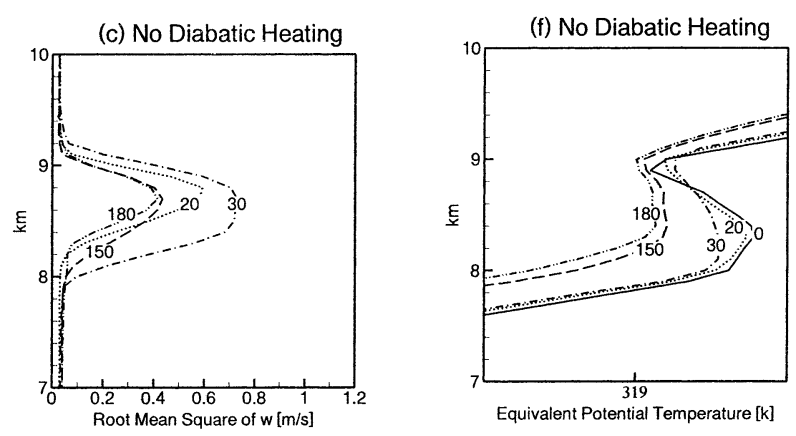

FIG. 22. Profiles of horizontally averaged (left) rms vertical velocity and (right) equivalent potential temperature for (a) and (d) daytime, (b) and (e) daytime without latent heating, and (c) and (f) no diabatic heating. Solid black curve represents initial profiles.

The effects of latent heating on the development of cirrus can be observed in profiles of root-mean-square vertical velocity and equivalent potential temperature (Fig. 22). For daytime cirrus with all the diabatic heating processes, the latent heat released during the growth period (the first $30 \mathrm{~min}$ ) provides energy for the initial perturbation to grow. As ice crystals grow larger and fall out of the generation region into a subsaturated layer, the vertical profile of latent heating warms the upper layer and cools the lower layer, thus serving to stabilize the cloud layer, as can be verified by the profiles of equivalent potential temperature (Fig. 22d). Without the negative feedback of the latent heating during the later stages of the simulation, the upper cloud layer is destabilized more by the radiative processes (Fig. 22e). Thus, the corresponding root-mean-square vertical velocity becomes as large as $1.1 \mathrm{~m} \mathrm{~s}^{-1}$ at $150 \mathrm{~min}$ without latent heating (Fig. 22b).

The corresponding profiles of horizontally averaged
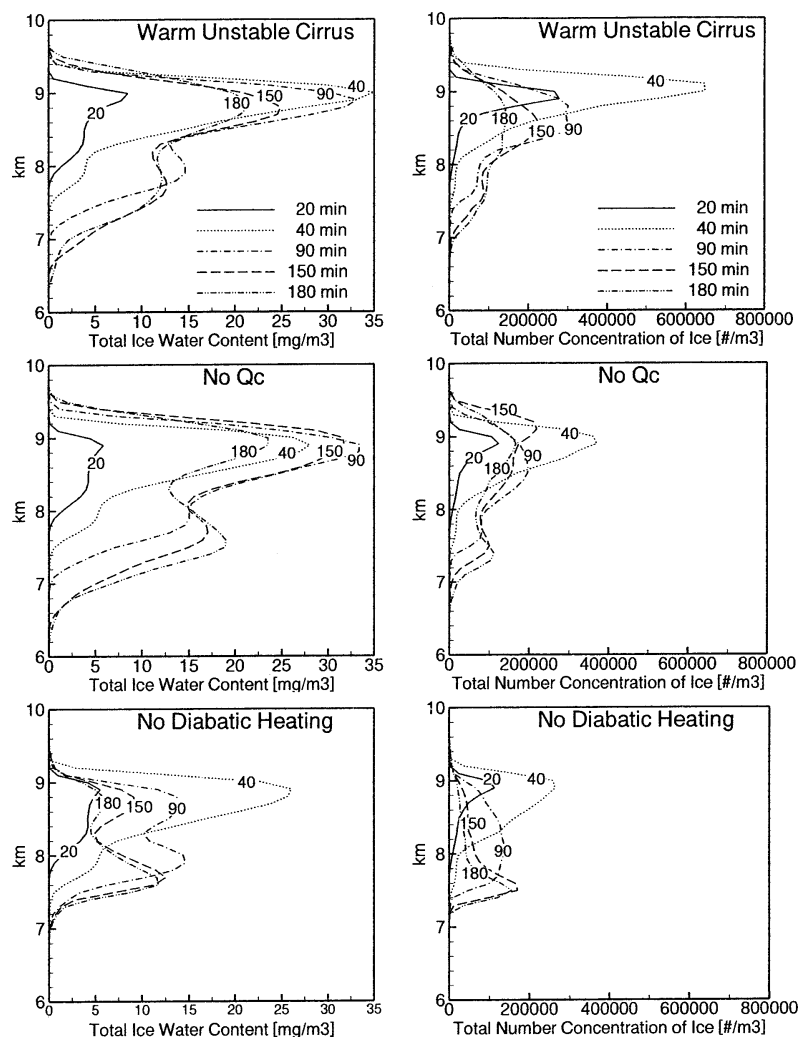

FIG. 23. Profiles of horizontally averaged ice water content and number concentration. The background profile is warm unstable. (top) Results for daytime with full diabatic heating. (middle) The results for daytime without latent heating. (bottom) The results without any diabatic heating.

ice water content and number concentration are shown in Fig. 23. The number concentration of ice without latent heating is smaller than with it, because the cloud is less buoyant during the growing stage (Figs. 23d,e), but the cloud also persists longer. On the other hand, the case with all diabatic heating turned off decays quickly (Figs. 23c,f).

\section{d. Simulation set IV: Effect of ice crystal habit on the development of cirrus}

This simulation set is designed to gauge the sensitivity of cirrus development to ice crystal habit. Four types of ice crystal are considered here: columns, plates, bullet rosettes, and spheres. The first three types are commonly observed in cirrus clouds, while the last one is a simplified approximation to ice particles. To focus on the effect of habit, we will first consider the development of cirrus in cold and warm stable atmospheres, but with the aggregation process turned off because of its insignificance in the stable environment. Then, we repeat the simulations for warm and cold unstable atmospheres but with the aggregation process turned on. Conditions in the simulation set are summarized in Table 2 .

The sensitivity of cirrus development to ice crystal 

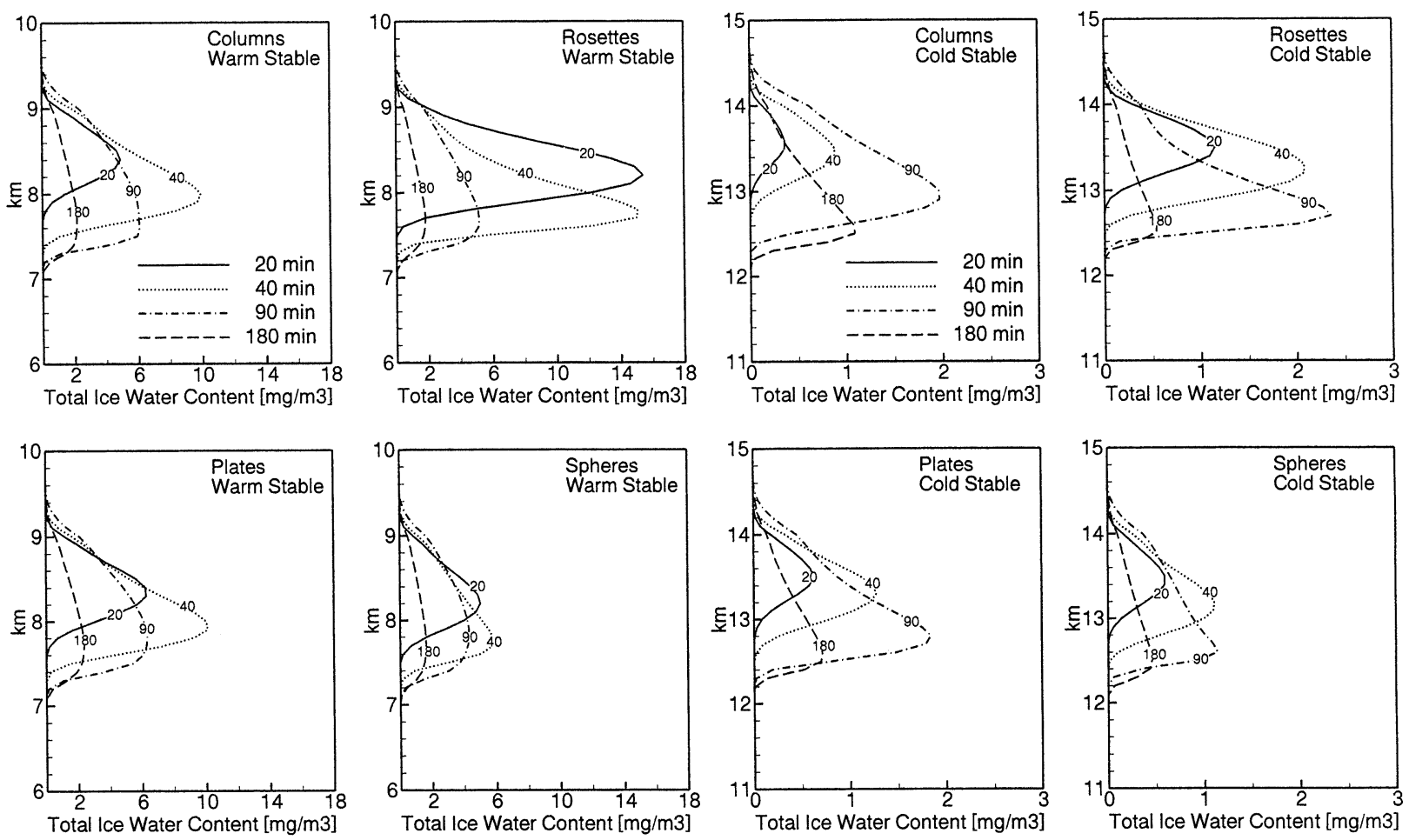

FIG. 24. Profiles of horizontally averaged ice water content for four different ice crystal types. (left two columns) The warm stable case, and (right two columns) the cold stable case.

habit can be seen in Fig. 24 for warm and cold cirrus. For the warm stable cases, the peak amplitudes of the ice water content all occur around $40 \mathrm{~min}$, but their values are strongly habit dependent. The maximum ice water content for cirrus consisting of rosettes is more than twice as large as for spheres. These maxima are similar for columns and plates and are larger than for spheres but smaller than for rosettes. The results for the cold stable case are similar, except that the ice water content reaches its maximum value around $90 \mathrm{~min}$.

The corresponding profiles of mean crystal size for the warm and cold stable cases are shown in Fig. 25. Rosettes are largest, followed by plates and columns, while spheres are the smallest. The difference in mean size between rosettes and spheres is as large as fourfold.

The corresponding radiative heating rates for the warm and cold stable cases are shown in Fig. 26. Although the ice water content profiles for columns and plates are similar (Fig. 24), the corresponding solar and IR heating rates are slightly larger for plates than for columns. It can be seen that the IR heating rate is more sensitive to ice crystal habit than the solar radiative heating rate is.

The differences among simulations with different ice habits may be explained on the basis of ice crystal capacitance. As explained in Part I, the capacitance is parameterized as a function of the maximum crystal diameter and habit. A plot of the capacitance as a function of mass and habit is shown in Fig. 27. For ice particles with the same mass, bullet rosettes have the largest capacitance, hence the greatest diffusional growth rate, followed by plates and columns, whereas spheres have the smallest. We have seen that the ice water content is generally largest for rosettes, with columns ranked second, plates third, and spheres last (Fig. 24). Although the capacitance of columns is larger than that of plates, the resulting ice water contents are almost the same. This may be because the differential radiative heating induced by plates is greater than that for columns, resulting in slightly stronger upward vertical motion for the plates and thus producing more ice water content than expected.

The above discussions made it clear that assuming spherical particles in cirrus modeling would have resulted in seriously underestimating the radiative impact. To make an accurate assessment of the radiative impact of cirrus clouds, it is important to have good observational data of not only the size but the shape distributions if ice crystals in them.

The domain-averaged ice water content and number concentration are shown in Fig. 28 for both the warm and cold stable cases. The effect of ice crystal habit is evident here, too. During the growing stage, rosettes tend to consume more water vapor and thus suppress the homogeneous nucleation process (the homogeneous freezing of haze solution droplets, as parameterized in Part I of the paper). Consequently, the ice number concentration for rosettes is less than that for the other ice 

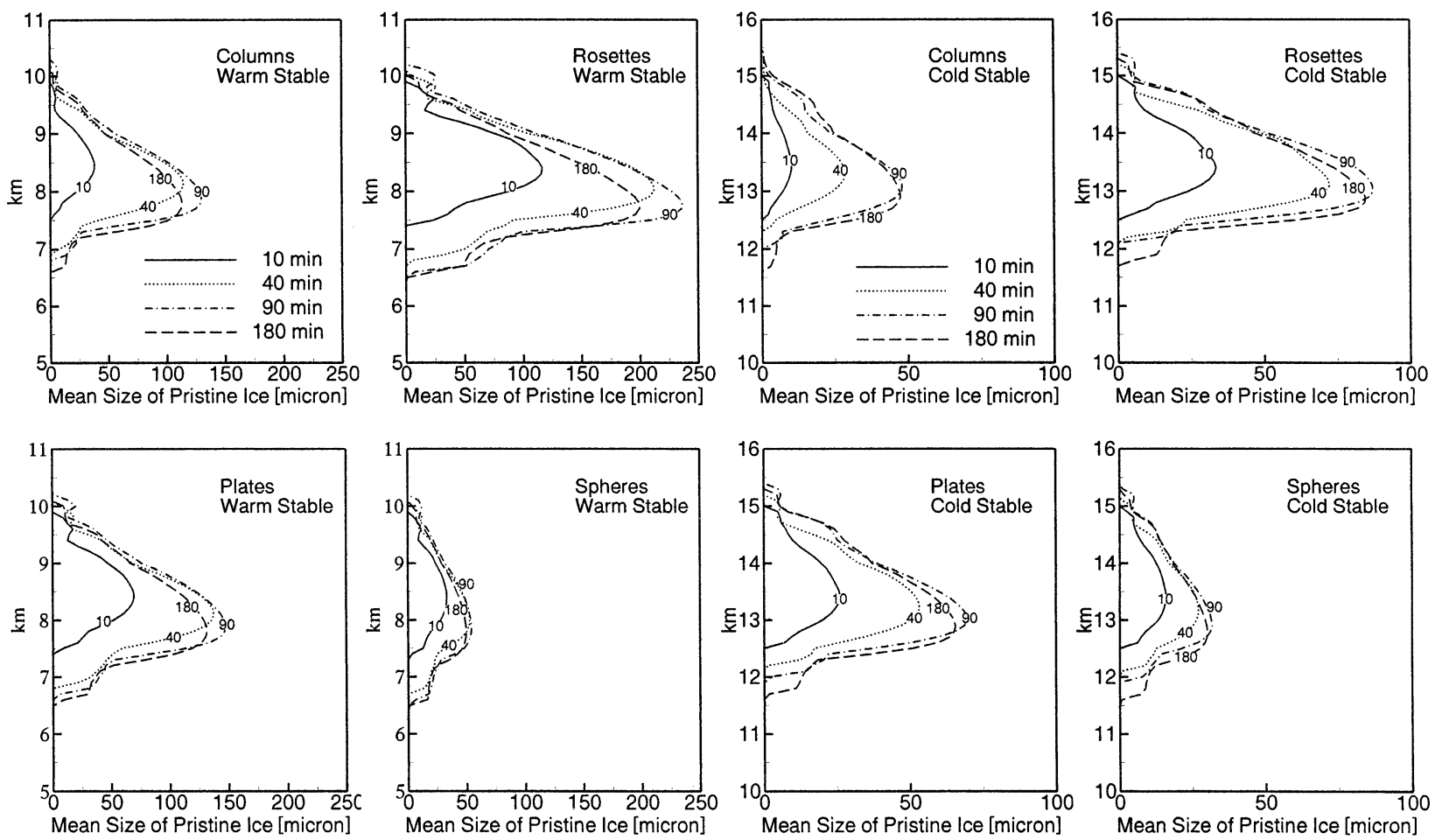

FIG. 25. Profiles of horizontally averaged mean ice crystal size for four different habits. (left two columns) The warm stable case, and (right two columns) the cold stable case.

habits. However, the resulting ice water content still exceeds those for the other ice habits because their large growth rates produce correspondingly larger crystals. This is also confirmed by the profiles of mean size for rosettes in Fig. 25, where the warm case at $10 \mathrm{~min}$ already shows a mean size in excess of $100 \mu \mathrm{m}$ for rosettes, while the other ice types still average less than $70 \mu \mathrm{m}$.

Simulations with columns and rosettes are also performed for the warm and cold unstable atmospheres. The effect of ice crystal habit on the development of cirrus is dramatic. The profiles of ice water content and number concentration for the warm and cold unstable cases are shown in Fig. 29. It is seen that there are dramatic differences in the number concentration of ice. This, again, results from the nature of the different growth rates for different ice crystal habits. Bullet rosettes, once formed by nucleation, consume more water vapor than columns, in turn, suppressing homogeneous nucleation during the growing stage of the cloud, so that the resulting ice number concentration for bullet rosettes is much less than for columns.

In simulation set IV, the aggregation process is active. The ice aggregates were found to be low in both number concentration and ice water content in simulation set I. Ice crystal aggregates have greater concentrations near the cloud base than higher up, and their sizes are much larger than pristine ice crystals. In order to understand the effect of the aggregation on cirrus development, four extra cases are performed in this simulation set as summarized in Table 2. We chose the column as the pristine ice habit, and then ran the model with and without aggregates for both the warm and cold stable atmospheres.

The results of those four simulations show that ice aggregates reduce the radiative heating rates, as seen from plots of both the solar and IR heating rates with and without aggregates in Fig. 30. It is evident that the differential heating of terrestrial radiation is greatly reduced by ice aggregates. Thus, the effect of aggregates on cirrus development is to reduce the optical depth of the cloud, and is likely to reduce the radiative destabilization of the cloud layer.

\section{Summary and conclusions}

In this paper, we have used the numerical cirrus cloud model developed in Part I to examine the development of cirrus for four different atmospheric environments: warm unstable, cold unstable, warm stable, and cold stable. These basic comparative experiments comprise simulation set I. Although the clouds in the warm and cold cases start with similar relative humidity conditions, they develop in very different ways. Results of more experiments using the same numerical model, simulation sets II through IV, have also been presented herein to elucidate the role of various physical properties in the development and maintenance of cirrus clouds.

In the warm unstable case of simulation set I, ice 

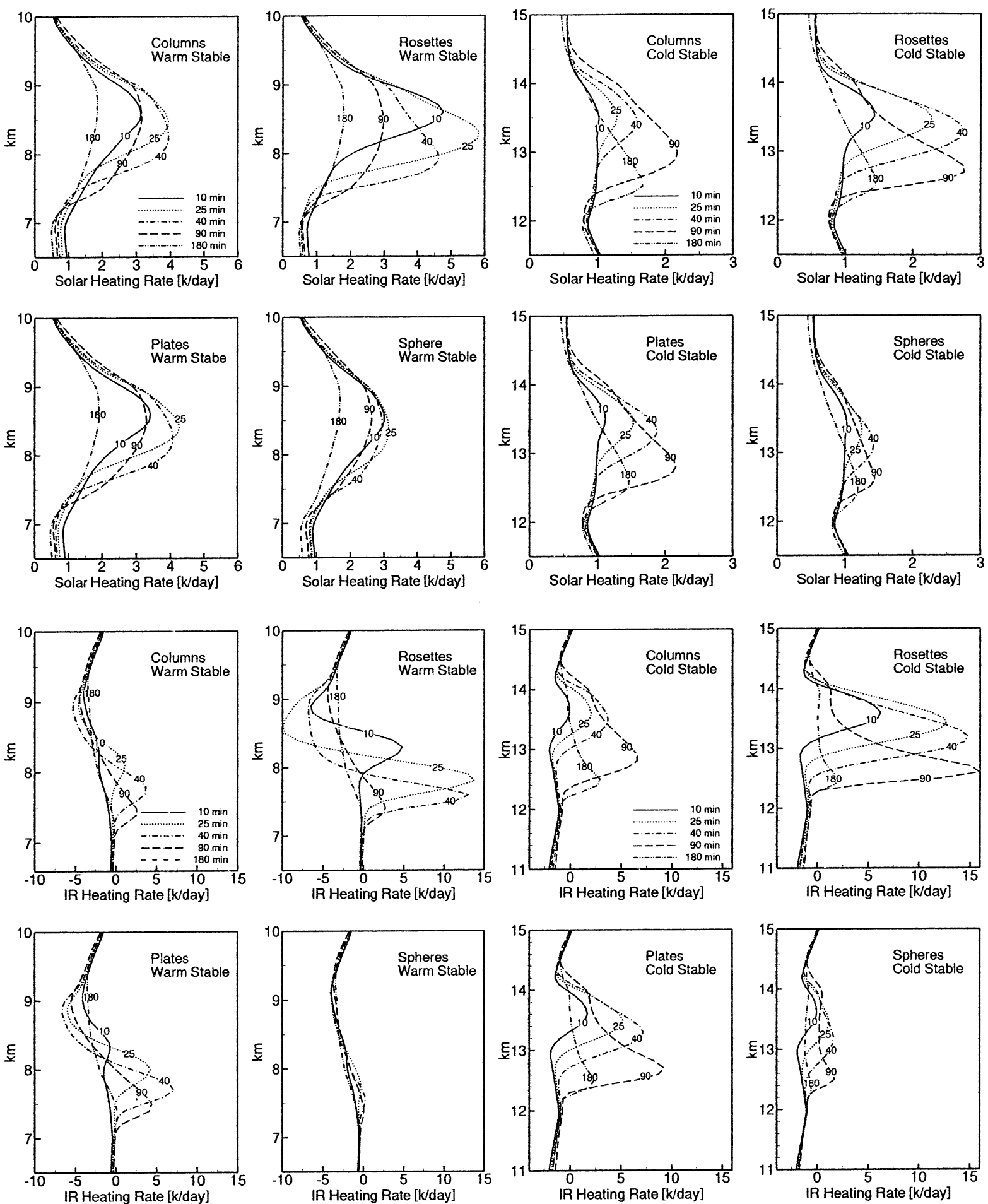

FIG. 26. Profiles of horizontally averaged solar heating rates and IR heating rates for four different ice crystal types. (left two columns) The warm stable case, and (right two columns) the cold stable case.

particles grow quickly during the early stage. Once they are large enough, at $\sim 40 \mathrm{~min}$, they start to fall out of the cloud generation region (initial supersaturated layer) into the subsaturated lower region. For the cold unstable case, however, most ice particles do not grow large enough to fall out of the cloud generation region, due to small growth rates at cold temperatures, so that most of the ice particles remain in the initial supersaturated 


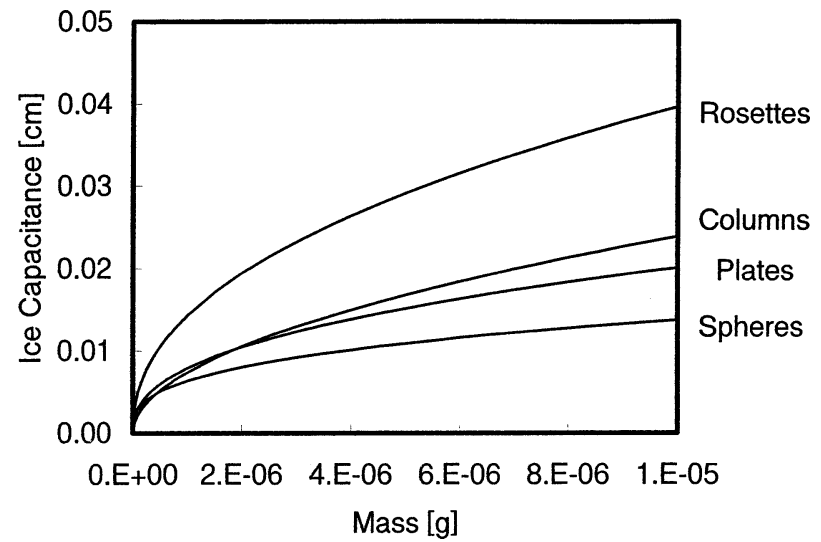

FIG. 27. Ice crystal capacitance as a function of ice crystal mass and habit.

region until $90 \mathrm{~min}$. Consequently, the cold cirrus tends to persist longer than the warm cirrus, mainly because of the contrast between ice crystal growth rates at different temperatures.

In the unstable cases of simulation set I, the diabatic heating tends to slightly destabilize the upper layer, so that the in-cloud circulation is still active during the later stages and is concentrated near the cloud top. This circulation can transport water vapor upward so that the upper part of the cloud remains moist and new ice particles are generated.

Whereas solar heating tends to be concentrated near the cloud top in both unstable cases, the IR heating effects are quite different for these two cases. In the warm case, the IR heating warms the lower part of the cloud and cools the upper part, whereas in the cold case most of the cloud layer is radiatively warmed. The major cause of this difference is that the cold cloud is optically thinner than the warm cloud. Therefore, the IR radiation coming from below can penetrate to the top of the cold cloud, so that its whole depth is warmed. In the warm case, on the other hand, the cloud layer is optically thick enough so that the radiation from below is absorbed short of the cloud top, and the IR warming thereby decreases with height and eventually reverses to cooling.

In the stable cases, homogeneous nucleation does not occur for the heterogeneous nucleation parameterization used. Therefore, the number concentration of ice crystals produced is much less than in the unstable cases. However, the individual ice crystals can grow larger, since there is less competition for water vapor among ice crystals. Hence, ice crystals fall out of the initial supersaturated layer faster than in the unstable cases. The sedimentation rate is slower in the cold stable case than in the warm stable one, again due to the slower growing and therefore smaller crystals at cold temperatures. In both stable cases, the induced diabatic heating does not destabilize the cloud layer.

These four case studies in simulation set I seem to
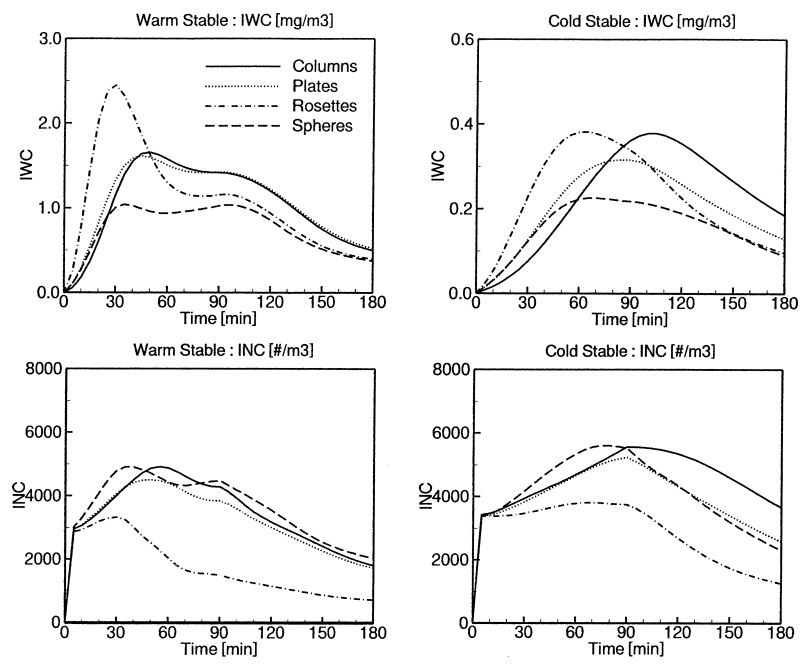

FIG. 28. Domain-averaged ice water content and number concentration for warm and cold stable cases.

suggest that homogeneous nucleation and cold temperature are two major reasons for persistent cirrus clouds. If homogeneous nucleation is involved, numerous ice crystals may be generated and the individual ice crystals are small due to the competition for water vapor. Small ice crystals fall slowly, so that most of the ice can stay in the initial supersaturated layer, leading to the persistent cirrus. Moreover, the abundant ice created by homogeneous nucleation allows sufficient latent heat release and radiative heating to induce upward vertical motion, with enough upward transport of water vapor so that the upper part of the cloud remains supersaturated and new ice crystals keep being generated near the cloud top. Although some ice crystals also sublimate away in the lower layer, enough new ice crystals are generated near the cloud top to maintain cirrus development. The other factor that contributes to the persistent cirrus is low temperature, which implies slow ice crystal growth so that most ice particles remain small and tend to stay in the initial supersaturated layer. In addition, the slow growth rate limits consumption of water vapor in the cloud layer, leaving ample water vapor available to be transported upward by the heatinginduced ascent. This transport keeps the upper part of the cloud moist enough to generate new ice crystals and hence persistent cirrus.

Simulation set II explores the effect of radiative processes. For a warm unstable atmosphere, daytime cirrus is more energetic and produces more ice water than nighttime cirrus. However, for a cold unstable atmosphere, the opposite is true. The simulations with and without radiative processes show that the radiative processes are very important factors in the maintenance of cirrus during the later stages. The radiative processes directly affect the intensity and structure of convective elements in the cloud layer. The vertical structure of the radiative heating modifies the static stability structure 

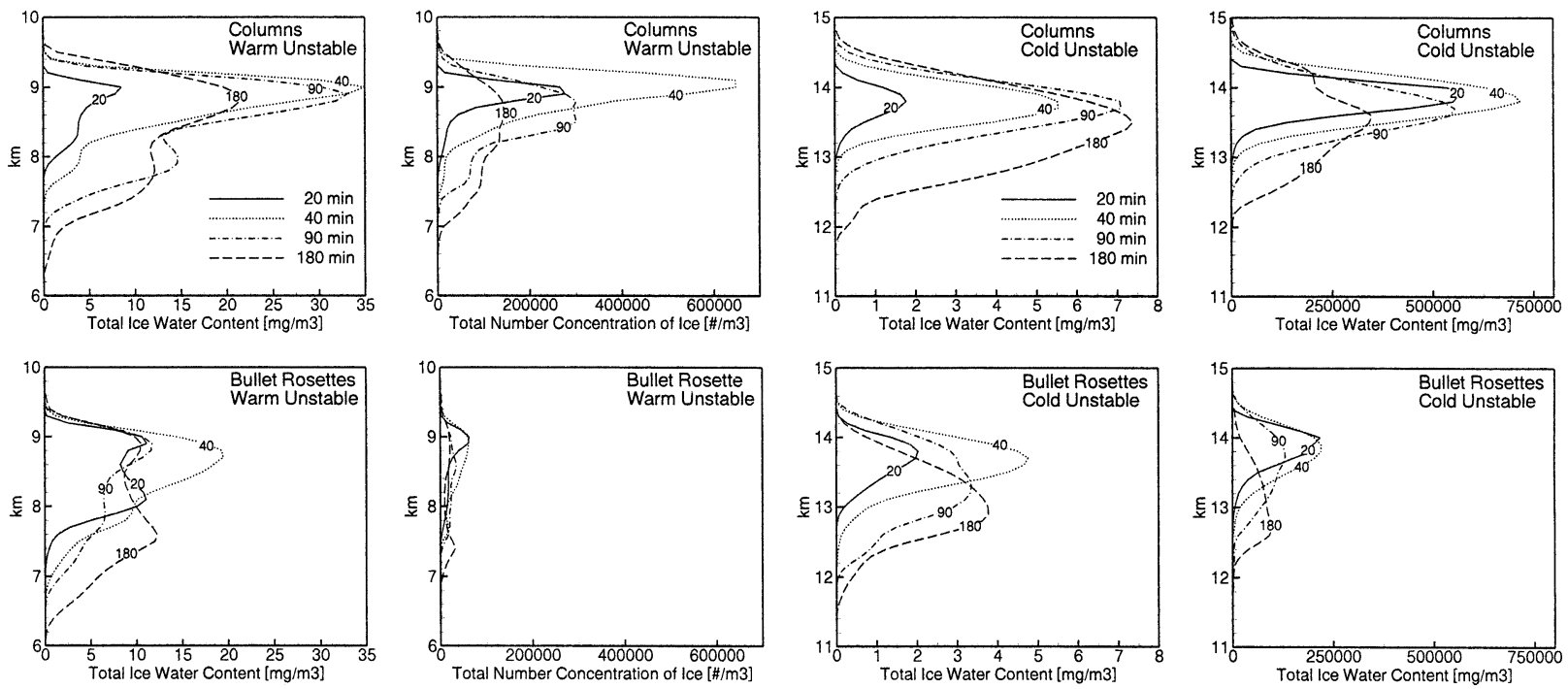

FIG. 29. Profiles of horizontally averaged ice water content and number concentration for columns and rosettes. (left two columns) The warm unstable case and (right two columns) the cold unstable case.

in the layer. Being cumulative, this effect is important to the longer-term development of the cloud layer.

Simulation set III investigates the role of latent heating in cirrus development. The results suggest that latent heating plays two different roles early versus later. It seems to provide energy for the initial perturbation to grow at first, and thus produces relatively many ice
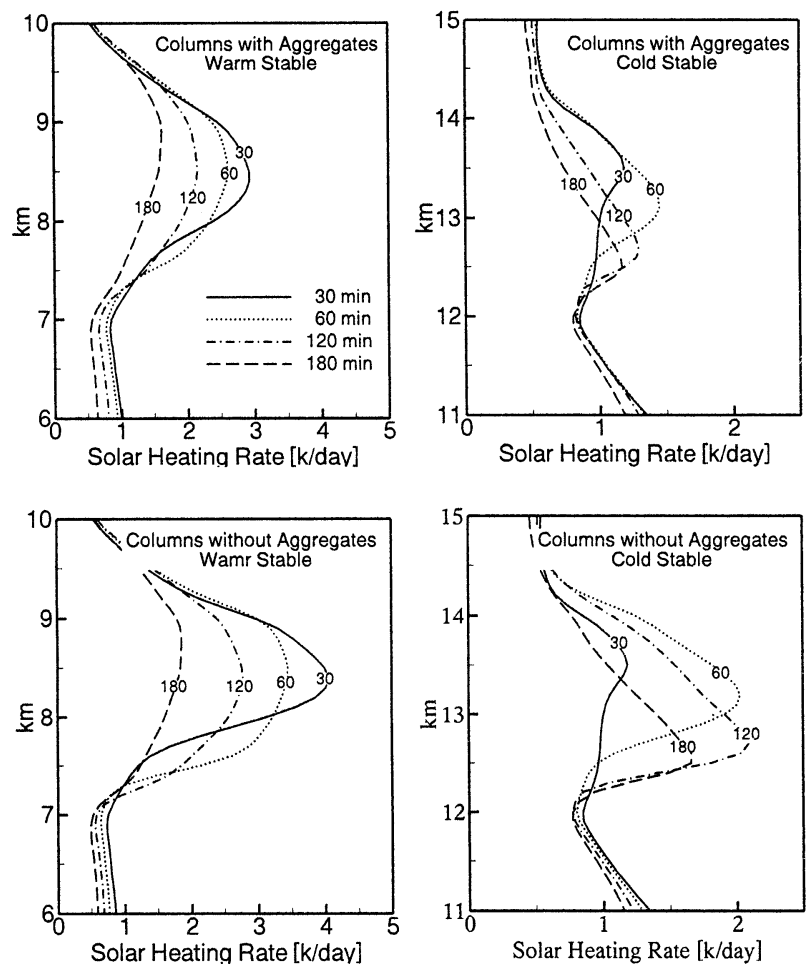

crystals, in turn providing positive feedback to early cloud development. On the other hand, it subsequently tends to stabilize the cloud layer. The ongoing nucleation processes and the growth of ice warm the upper layer, and the ice crystal sedimentation into the subsaturated layers below creates sublimational cooling in the lower layer. This diabatic heating pattern of warming
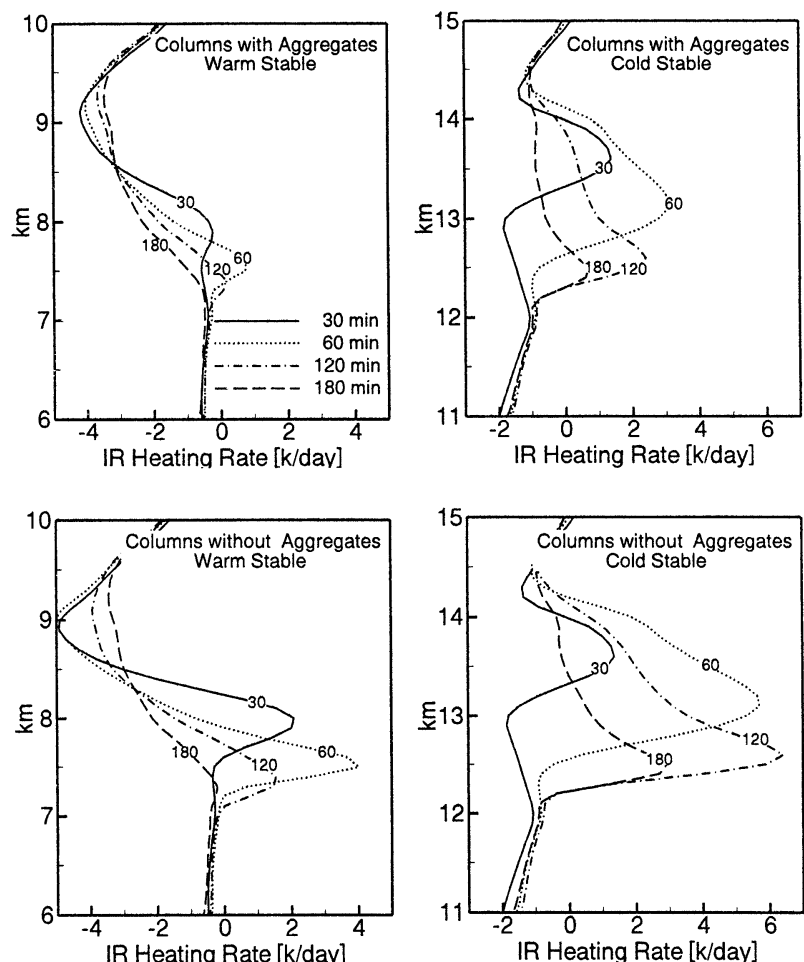

FIG. 30. Profiles of horizontally averaged solar and IR heating rates for simulations with and without aggregation process, shown for cold and warm stable cases, respectively. (left two columns) Solar heating rates, and (right two columns) the comparison for IR heating rates. 
at the top and cooling at the base is strong in the later stages of the cloud development and tends to stabilize the cloud.

Finally, simulation set IV examines the influences of ice crystal habit and the aggregation process on cirrus development. It is found that the cloud development is very sensitive to the ice crystal habit. This is mainly because the different ice crystal habits have distinctly contrasting capacitances, ventilation coefficients and optical properties, and all these factors contribute differently to ice crystal growth rates and hence to cloud development. The most important factor is the capacitance; among ice particles of a given mass, rosettes have the greatest capacitance and hence the largest growth rate, with successively smaller capacitances for columns, hexagonal plates, and spherical particles. Bullet rosettes generally grow two to three times faster than for other crystal types. The ice crystal habit influences homogeneous nucleation process. Bullet rosettes consume large amounts of the water vapor available in the cloud layer, due to their large growth rates, and thus severely suppress the initial nucleation process. As a result, cirrus clouds consisting of bullet rosettes have much fewer ice crystals nucleated than those with other ice crystal types. The IR heating rate is also more sensitive to ice crystal habit than the solar heating rate is. The role of aggregation in the development of cirrus is also examined; it tends to reduce the optical depth of the cloud and is thus likely to reduce the radiative destabilization of the cloud layer.

Acknowledgments. This research is partially supported by NSF Grants ATM-9314465, 9633424, 9714158, 9907761, and 0234744. One of us (PKW) would like to thank the Alexander von Humboldt Foundation of Germany for the Humboldt Award that supported his research visit to the University of Mainz, Germany, in 1993. He also thanks the Johnson Wax Corporation of Racine, Wisconsin, for a Samuel C. Johnson Distinguished Fellowship in 1993.

\section{REFERENCES}

Ackerman, T. P., N. K. Liou, F. P. J. Valero, and L. Pfister, 1988: Heating rates in tropical anvils. J. Atmos. Sci., 45, 1606-1623.

$\mathrm{Gu}$, Y., and K. N. Liou, 1997a: Interactions of radiation, microphysics, and turbulence in a two-dimensional cirrus cloud model. IRS '96: Current Problems in Atmospheric Radiation, W. L. Smith and K. Stamnes, Eds., A. Deepak, 238-241.

__ and _ 1997b: Numerical experiments on the interactions of various physical processes in cirrus clouds. Preprints, Ninth Conf. on Atmospheric Radiation, Long Beach, CA, Amer. Meteor. Soc., 97-101.

— , and —_, 2000: Interactions of radiation, microphysics, and turbulence in the evolution of cirrus clouds. J. Atmos. Sci., 57, $2463-2479$.

Gultepe, I., and D. O'C. Starr, 1995: Dynamical structure and turbulence in cirrus clouds: Aircraft observations during FIRE. $J$. Atmos. Sci., 52, 4159-4182.

Jensen, E. J., O. B. Toon, D. L. Westphal, S. Kinne, and A. J. Heymsfield, 1994a: Microphysical modeling of cirrus: 1. Comparison with 1986 FIRE IFO measurements. J. Geophys. Res., 99, $10421-10442$.

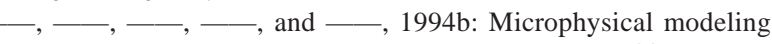
of cirrus: 2. Sensitivity studies. J. Geophys. Res., 99, $10443-$ 10454.

Lin, R.-F., 1997: A numerical study of the evolution of nocturnal cirrus by a two-dimensional model with explicit microphysics. Ph.D. dissertation, The Pennsylvania State University, 198 pp. [Available from The Department of Meteorology, The Pennsylvania State University, University Park, PA 16802.]

Liu, H.-L., P. K. Wang, and R. E. Schlesinger, 2003: A numerical study of cirrus clouds. Part I: Model description. J. Atmos. Sci., in press.

Starr, D. O'C., and S. K. Cox, 1985a: Cirrus clouds. Part I: A cirrus cloud model. J. Atmos. Sci., 42, 2663-2681.

_ , and — 1985b: Cirrus clouds. Part II: Numerical experiments on the formation and maintenance of cirrus. J. Atmos. Sci., 42, 2682-2694 